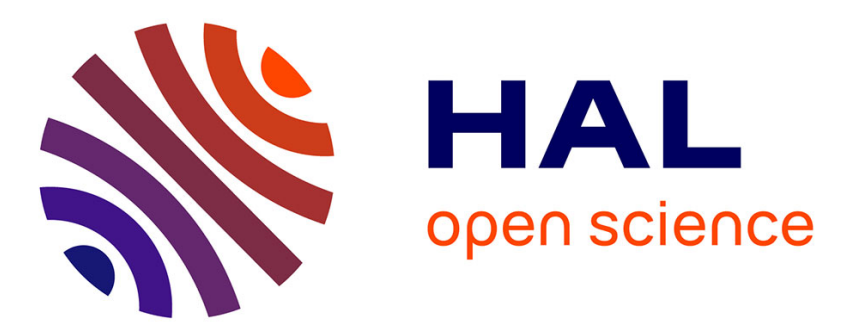

\title{
A model of tetrahydrofuran low-temperature oxidation based on theoretically calculated rate constants
}

Yann Fenard, Adrià Gil, Guillaume Vanhove, Hans-Heinrich Carstensen, Kevin M van Geem, Phillip R Westmoreland, Olivier Herbinet, Frédérique Battin-Leclerc

\section{To cite this version:}

Yann Fenard, Adrià Gil, Guillaume Vanhove, Hans-Heinrich Carstensen, Kevin M van Geem, et al.. A model of tetrahydrofuran low-temperature oxidation based on theoretically calculated rate constants. Combustion and Flame, 2018, 191, pp.252-269. 10.1016/j.combustflame.2018.01.006 . hal-01700660

\section{HAL Id: hal-01700660 \\ https://hal.science/hal-01700660}

Submitted on 20 Feb 2018

HAL is a multi-disciplinary open access archive for the deposit and dissemination of scientific research documents, whether they are published or not. The documents may come from teaching and research institutions in France or abroad, or from public or private research centers.
L'archive ouverte pluridisciplinaire $\mathbf{H A L}$, est destinée au dépôt et à la diffusion de documents scientifiques de niveau recherche, publiés ou non, émanant des établissements d'enseignement et de recherche français ou étrangers, des laboratoires publics ou privés. 


\title{
A model of tetrahydrofuran low-temperature oxidation based on theoretically calculated rate constants
}

\author{
Yann Fenard', Adrià Gil'², Guillaume Vanhove1, Hans-Heinrich Carstensen ${ }^{3}$, Kevin M. Van \\ Geem $^{3}$, Phillip R. Westmoreland ${ }^{4}$, Olivier Herbinet ${ }^{5}$, Frédérique Battin-Leclerc ${ }^{5}$,
}

\begin{abstract}
${ }^{1}$ CNRS, UMR 8522 - PC2A - Physicochimie des Processus de Combustion et de l'Atmosphère, University of Lille, F-59000 Lille, France

${ }^{2}$ Centro de Química e Bioquímica, DQB, Faculdade de Ciências da Universidade de Lisboa, Campo Grande, 1749-016 Lisboa, Portugal

${ }^{3}$ Laboratory for Chemical Technology (LCT), Ghent University, Technologiepark 914, 9052 Gent, Belgium

${ }^{4}$ Department of Chemical \& Biomolecular Engineering, North Carolina State University, Raleigh, NC, 276957905 USA

${ }^{5}$ Laboratoire Réactions et Génie des Procédés, CNRS, University of Lorraine, Nancy, France
\end{abstract}

Published in Combustion and Flame (2018), 191, 252-269

\begin{abstract}
The first detailed kinetic model of the low-temperature oxidation of tetrahydrofuran has been developed. Thermochemical and kinetic data related to the most important elementary reactions have been derived from ab initio calculations at the CBS-QB3 level of theory. A comparison of the rate constants at $600 \mathrm{~K}$, obtained from these calculations with values estimated using recently published rate rules for alkanes, sometimes show differences of several orders of magnitude for alkylperoxy radical isomerizations, $\mathrm{HO}_{2}$-eliminations, and oxirane formations. The new model satisfactorily reproduces previously published ignition delay times obtained in a rapid-compression machine and in a shock tube, as well as numerous product mole fractions measured in a jet-stirred reactor at low to intermediate temperatures and in a low-pressure laminar premixed flame. To highlight the most significant reaction pathways, flow-rate and sensitivity analyses have been performed with this new model.
\end{abstract}

Keywords : Low-temperature oxidation; Tetrahydrofuran; Modeling; CBS-QB3 calculations 


\section{Introduction}

It is now well established that the use of traditional fossil fuels is largely responsible for current environmental issues such as climate change. An efficient way to reduce $\mathrm{CO}_{2}$ emissions while still making use of internal combustion engine technology and of the infrastructures build around liquid fuel usage is to shift from hydrocarbon fossil fuels to biofuels. Unlike first-generation biofuels whose synthesis is in competition with agricultural food production, second generation biofuels are produced from other types of biomass, such as lignocellulosic biomass, which is not part of the food chain [1]. Acquiring a thorough understanding of the combustion chemistry and emission levels is a crucial prerequisite before any type of bio derived molecule can be considered as fuel for wide use in engines.

Biomass contains a variety of substituted five- and six-membered cyclic components, and strategies are being developed to transform biomass into suitable transportation fuels that retain these structures. Saturated cyclic ethers of the family of tetrahydrofuran (THF) can be obtained from carbohydrates or cellulosic biomass by catalytic processes [2]. Thanks to their heating values being close to that of gasoline, these ethers have the potential to become promising bio-fuels for internal combustion engines [3]. Initial engine tests for this family of compounds showed satisfactory performances, with power outputs and emissions close to that of unleaded fuels [4].

THF and other saturated cyclic ethers are also well-known primary products of the low-temperature oxidation of alkanes [5]. Consequently, any improvement of the understanding of the low-temperature oxidation of these cyclic oxygenated compounds will also help to improve model predictions of alkane oxidation.

Two kinetic models for the high-temperature THF oxidation can be found in the literature. The first detailed reaction mechanism containing 71 species and 484 reactions was proposed by Dagaut et al. [6] in 1998. This model was validated against experimental data obtained in a shock tube and in a jet-stirred reactor, respectively (covering a temperature range from 800 to $1800 \mathrm{~K}$, pressures (p) from 202 to $1013 \mathrm{kPa}$ and equivalence ratios $(\varphi)$ from 0.5 to 2). More recently, Tran et al. [3] published a detailed reaction mechanism for THF oxidation that contains 255 species and 1723 reactions. The rate expressions of the most important reactions were calculated with ab initio methods. This last model was validated for pressures from 6.7 to $8550 \mathrm{kPa}$ and equivalence ratios ranging from 0.5 to 2 against species profiles measured in a low-pressure premixed flame, adiabatic laminar burning velocity measurements for an atmospheric pressure premixed flame, and ignition delay times measured in a shock tube. The two previous kinetic models do not include low-temperature oxidation pathways, i.e. the formation and consumption of tetrahydrofuranylperoxy radicals.

Three experimental studies of the low-temperature oxidation of THF have recently been published. In 2014, Uygun et al. [7] studied THF ignition delay times in a shock tube for temperatures ranging from 691 to $1100 \mathrm{~K}$, at 2.0 and 4.0 MPa for stoichiometric mixtures. In 2015, Vanhove et al. reported ignition delay times measured in a rapid-compression machine and product mole fractions obtained in a jet-stirred reactor for temperatures ranging from 500 to $1100 \mathrm{~K}$, pressures from 0.1 to $1.0 \mathrm{MPa}$, and $\varphi$ from 0.5 to 2 [8]. In 2016, Antonov et al. [9] presented a combined experimental and quantum chemistry study of the initial THF 
oxidation reactions in the temperature range $550-650 \mathrm{~K}$ and at pressures between 1.3 and $266.6 \mathrm{kPa}$. Several intermediates were detected using synchrotron-based photoionization mass spectrometry. In order to qualitatively explain the formation of intermediates, potential energy surfaces were calculated for molecular oxygen addition to the two THF radicals formed by hydrogen abstraction reactions from THF. However, no rate constant was reported. Therefore, despite these three experimental studies of the low-temperature THF oxidation, to the best of our knowledge no related detailed kinetic model is available that can reproduce these data.

Three detailed kinetic models have been recently published for the low-temperature oxidation of substituted THF, which are actually considered promising biofuels. Fenard et al. [10] presented a model of the lowtemperature oxidation of 2-methyltetrahydrofuran validated using ignition delay times and mole fraction profiles obtained in a rapid-compression machine. Tripathi et al. [11] also developed a model of the lowtemperature oxidation of 2-methyltetrahydrofuran. This model was validated using ignition delay times from both a rapid-compression machine and a high-pressure shock tube. Cai et al. [12] described a model for the low-temperature oxidation of 2-butyltetrahydrofuran validated using ignition delay times obtained in a rapid-compression machine and in a shock tube. However, in these three models, the rate constants of the reactions important at low temperatures have been estimated based on the kinetic rate rules that have been developed for alkanes.

This review of previous work shows the need for a new model for the THF oxidation at low temperature based on theoretically calculated rate constants. Such a mechanism will also serve as the core model for the development of low-temperature oxidation models for similar molecules containing a saturated fivemember ring cyclic ether moiety. Several such molecules have been proposed as potential biofuels. The development of such a model is thus the primary aim of the present paper. This model builds on the wellvalidated high-temperature oxidation model of Tran et al. [3], which is extended using results from highlevel theoretical calculations for the reactions important at low-temperature. Through validation against the experimental data obtained by Vanhove et al. using a rapid-compression machine and a jet-stirred reactor [8] and by Uygun et al. [7] in a shock tube, as well as against the measurements reported by Dagaut et al. [6] and by Tran et al. [3], it is shown that this new model is capable to predict the important features of low temperature oxidation and ignition of THF/oxygen mixtures quite well.

\section{High-level theoretical calculations of thermochemical and kinetic data and kinetic simulation methodology}

Thermochemical properties for numerous reactions important to model the THF low-temperature oxidation have been calculated using the CBS-QB3 method. Calculated C-H bond dissociation energies (BDE) for THF molecule are given in Figure S1 supplementary Material: C-H BDE are notably lower in alpha position of the 0 -atom. These reactions are described in detail in the model generation section. Here we discuss the calculation methodology and compare results for the potential energy surfaces of the first oxygen addition to THF radicals with a previous study [9]. Afterwards, the methodology used for kinetic simulations is introduced. 


\subsection{Computational methods}

Rate coefficients were calculated in two steps. First, electronic structures were calculated at the CBS-QB3 level of theory [13] using the Gaussian 09 revision D suite of programs [14]. Although cyclic molecules are restricted in torsional motion and their number of conformers is usually small, this changes once substituents are added and several conformations can be generated due to single-bond rotations. This is the case of the hydroperoxyl group for which there are torsions associated to the C-C-O-O group of atoms and some associated to the $\mathrm{C}-\mathrm{O}-\mathrm{O}-\mathrm{H}$ group. Thus, in order to carry out a conformational search associated with such rotamers to find the global minima, the following strategy was applied. First, we performed a systematic conformational search by rotating each single bond associated to C-C-O-O and C-O-O-H torsions by steps of $120^{\circ}$ taking into account the alternated conformations. We obtained a total of 9 rotamers which were subsequently optimized at B3LYP/6-31G(d,p) level [15]. On the other hand, radical intermediate structures were then obtained by substraction of one $\mathrm{H}$ atom from several positions of the structure. Finally, we used the Transition State Search using Chemical Dynamics Simulations with the TSSCDS software $[16,17]$ to obtain the transition state structures associated with the studied reactions. Intrinsic reaction coordinate (IRC) calculations were also carried out to confirm that the transition states linked the expected reactants, intermediates and products. Subsequently, all these stationary points of the Potential Energy Surfaces (PESs) were recalculated at CBS-QB3 level [12]. The unrestricted formalism was considered for the open shell systems. In all cases, spin contamination was found to be small as the S2 expectation values were very close to 0.75 . The optimized geometries related to the main species presented in Figure 1 are given in Table S1 in Supplementary Material.

Thermodynamic properties were calculated based on the CBS-QB3 results using methods from statistical mechanics. Electronic energies are converted into enthalpies of formation using the atomization method [18]. For rate coefficient calculations, these enthalpy values were used without further corrections as only relative enthalpies are needed. For the thermodynamic database, the enthalpies were corrected for neglected spin-orbit contributions and for systematic deviations (bond additive corrections, BAC). Internal rotations around single bonds were treated as hindered rotors using common practices. The hindrance potentials obtained at the B3LYP/6-31G(d) were also used to identify conformers of possibly lower energy as discussed above.

Finally, the thermodynamic data of molecules and radicals was stored in form of NASA polynomials under the Chemkin format [19]. Table S2 in Supplementary Material presents the theoretically calculated thermochemical data $\left(\Delta_{f} H_{298 K}^{\circ}, S_{298 K}^{\circ}\right.$ and $\left.C p^{\circ}(T)\right)$ for the important species.

In the second step, transition state theory expressed in terms of Gibbs free energies was used to calculate the rate coefficients:

$$
k_{T S T}(T)=\chi(T) \cdot \frac{k_{B} T}{h} \cdot\left(\frac{R T}{p}\right)^{\Delta n-1} \cdot e^{-\frac{\Delta G^{\ddagger}}{R T}}
$$

with $\Delta G^{\ddagger}$ being the Gibbs free energy difference between transition state without the transitional mode and reactant(s), $\Delta n$ the molecularity of the reaction ( 2 for bimolecular, 1 for unimolecular reactions), $\chi(T)$ a 
correction factor that accounts for quantum mechanical tunneling calculated using the asymmetric Eckart potential, $h$ the Planck constant, $R$ the gas constant, $P$ pressure and $T$ temperature. Gibbs free energies were obtained from the NASA polynomials calculated as described above. Rate coefficients were calculated for temperatures ranging between $300 \mathrm{~K}$ and $2500 \mathrm{~K}$ in $50 \mathrm{~K}$ steps. The individual rate coefficients were finally regressed to modified Arrhenius expressions.

\subsection{Tetrahydrofuranperoxy radical potential energy surfaces}

Important stationary points on the potential energy surfaces of the low-temperature reactions of the tetrahydrofuran-2-peroxy ( $\alpha$-ROO in Figure 1 ) and tetrahydrofuran-3-peroxy ( $\beta$-ROO in Figure 1 ) radicals have been calculated in the present work. The $0 \mathrm{~K}$ energies are shown in Figure 1 together with results obtained by Antonov et al. [9]. Note that the current calculations were performed using essentially the same level of theory as Antonov et al. [9], hence the results, although obtained independently, should be almost identical. One difference is that Antonov et al. [9] used the software KinBot to explore this PES automatically, while the current study constructed the PES manually. We expect and confirmed in some cases that observed differences are caused by the use of different geometries for the lowest energy conformer. The efficient identification of global minima on the PES remains a challenging task.

In the following discussion and in Figure 1, the nomenclature introduced by Antonov et al. [9] is used. The letters " $\alpha$ " and " $\beta$ " indicate the carbon atoms next to the ether oxygen or one position further away, respectively. QOOH radicals are distinguished with two $\alpha / \beta$ prefixes, the first one indicating the position of the $\mathrm{OOH}$ group and the second one that of the radical site. A prime is used if the radical site is located opposite to the $\mathrm{OOH}$ group.

Figure 1a shows the reaction pathways originating from $\mathrm{O}_{2}$ addition to THF-2-yl forming the 2-peroxyltetrahydrofuranyl $(\alpha-\mathrm{ROO})$ radical. A comparison between the current $0 \mathrm{~K}$ energies and those calculated by Antonov et al. [9] shows that the majority of values agree within $0.1 \mathrm{kcal} / \mathrm{mol}$. However, there are a few exceptions. First, the energies for all three QOOH isomers of $\alpha$-ROO calculated by this study are clearly lower than those published by Antonov et al. [9]. For $\alpha \beta$-QOOH radical, the present relative energy is $10.8 \mathrm{kcal} / \mathrm{mol}$ vs. $15.0 \mathrm{kcal} / \mathrm{mol}$ [9], suggesting that $\alpha \beta-Q 00 \mathrm{H}$ radical is significantly more stable than previously predicted. Note that the calculated barrier for its formation from $\alpha$-ROO is also lower but only by $0.9 \mathrm{kcal} / \mathrm{mol}$ compared to the values proposed by Antonov et al. [9], and the barrier for its $\beta$-scission reaction leading to 1,2-dihydrofuran and $\mathrm{HO}_{2}$ radicals is $2.8 \mathrm{kcal} / \mathrm{mol}$ lower than reported. The difference in the $0 \mathrm{~K}$ energy for $\alpha \beta^{\prime}-\mathrm{QOOH}$ radical is also $2.8 \mathrm{kcal} / \mathrm{mol}$, while that for $\alpha \alpha^{\prime}-\mathrm{QOOH}$ radical is just $0.8 \mathrm{kcal} / \mathrm{mol}$.

Despite these differences, the general features of this PES are the same as already discussed in detail by Antonov et al. [9]. The large well depth of $36.8 \mathrm{kcal} / \mathrm{mol}(0 \mathrm{~K})$ of $\alpha-\mathrm{ROO}$ makes this radical rather stable with respect to re-dissociation and thus enables low-temperature chemistry to occur. The concerted elimination channel with a barrier of only $28.8 \mathrm{kcal} / \mathrm{mol}, 8 \mathrm{kcal} / \mathrm{mol}$ below the entrance channel at $0 \mathrm{~K}$, might contribute significantly to the $\alpha$-ROO radical consumption. It should compete with the $\beta$-scission pathway proceeding via the $\alpha \alpha^{\prime}-\mathrm{QOOH}$ to form butanedial (succinaldehyde) and $\mathrm{OH}$, which has a low barrier of $26.7 \mathrm{kcal} / \mathrm{mol}$. Note that although a reaction path is conceivable, in which $\alpha \alpha^{\prime}-\mathrm{QOOH}$ undergoes a ring closure to form bicyclo[2,1,1] 5,6-dioxa-hexane, a bicyclic ether, together with an $\mathrm{OH}$ radical, all attempts failed to locate a 
proper transition state for this reaction. If formed, this bicyclic diether would immediately decompose to butanedial in a concerted reaction, but the unsuccessful trials to characterize the transition state suggest that this reaction sequence is not important.
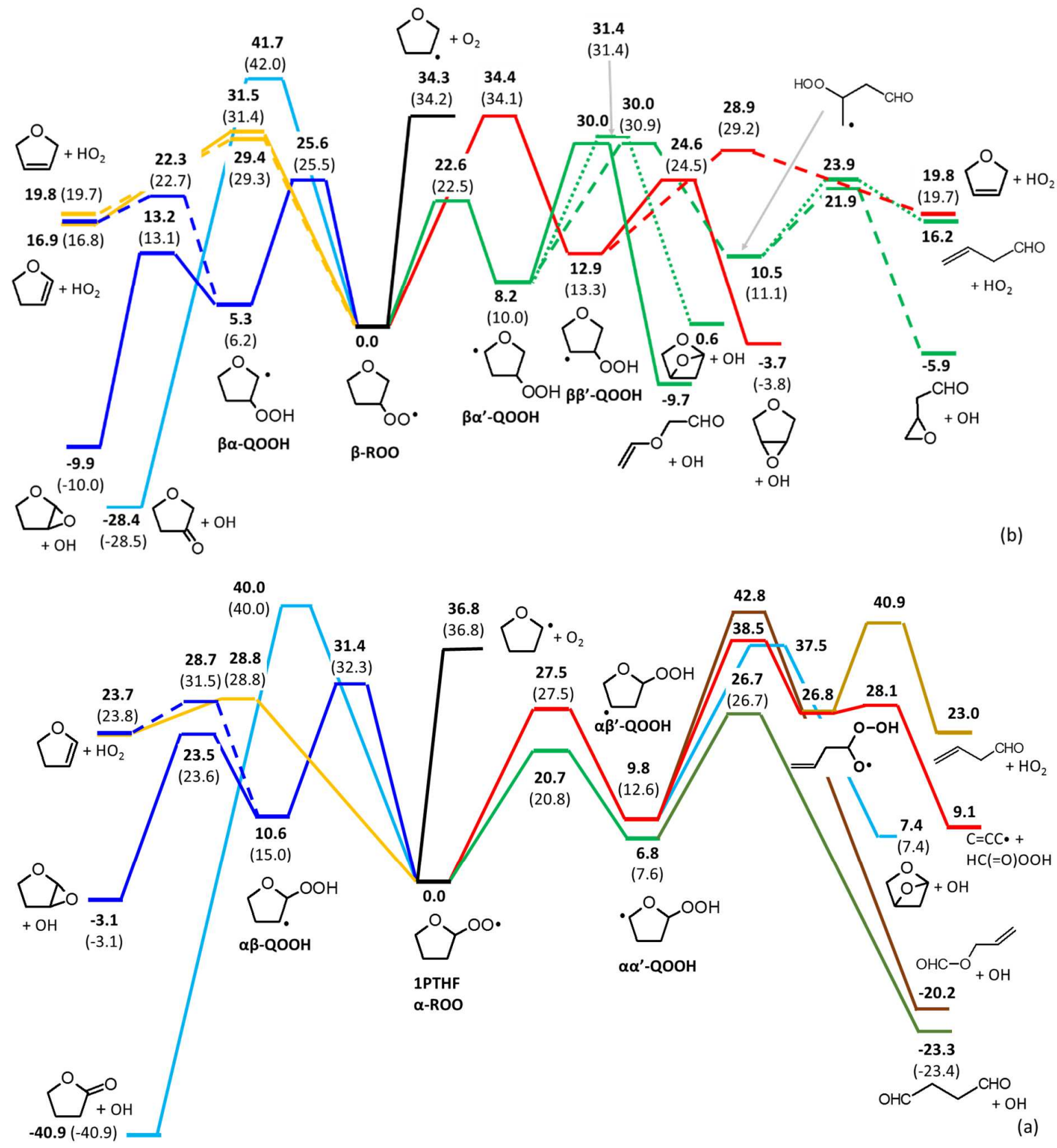

Figure 1 : Potential energy surfaces of the low-temperature reactions of (a) the tetrahydrofuran-2-peroxy $(\alpha-\mathrm{ROO})$ and (b) tetrahydrofuran-3-peroxy $(\beta-\mathrm{ROO})$ radicals calculated in the present work. The values are $0 \mathrm{~K}$ energies in kcal mol-1 relative to the initial peroxyl radicals. The corresponding results from Antonov et al. [9] are given in parentheses. 
The reaction pathway with the next-lowest overall barrier is the isomerization of $\alpha$-ROO to $\alpha \beta$-QOOH radical followed by bicyclic ether formation and $\mathrm{OH}$ radical release. Given the high barriers, neither the 1,3 $\mathrm{H}$-shift reaction of $\alpha$-ROO radical producing $\gamma$-butyrolactone and $\mathrm{OH}$ nor the product channels of $\alpha \beta^{\prime}$-QOOH radical are expected to contribute to the reactivity because the associated barriers are higher than the entrance channel. A more detailed analysis of this PES can be found in Antonov et al. [9].

Turning to Figure $1 \mathrm{~b}$ and the $\beta$-ROO radical-related PES, one can again observe that most $0 \mathrm{~K}$ energies calculated in this current study agree very well (within $+/-0.1 \mathrm{kcal} / \mathrm{mol}$ ) with the corresponding values found by Antonov et al. [9]. Small differences exist for the relative energies of the QOOH isomers: $\beta \alpha-Q O O H$ radical is found to be $0.9 \mathrm{kcal} / \mathrm{mol}$ more stable in this work compared to the previous study [9]. For $\beta \alpha^{\prime}-\mathrm{QOOH}$ radical, the difference is $1.8 \mathrm{kcal} / \mathrm{mol}$, and for $\beta \beta^{\prime}-\mathrm{QOOH}$ radical, the difference is $0.4 \mathrm{kcal} / \mathrm{mol}$. Another small difference is seen for the 4-oxo,2-hydroperoxybutyl radical, for which $0 \mathrm{~K}$ energies of $10.5 \mathrm{kcal} / \mathrm{mol}$ and $11.1 \mathrm{kcal} / \mathrm{mol}$ [9] are reported.

Compared to that of an $\alpha$-ROO radical, the PES section related to a $\beta$-ROO radical is significantly more complex. The R-O bond energy of $\beta$-ROO radical $0 \mathrm{~K}$ is only $34.3 \mathrm{kcal} / \mathrm{mol}$ compared to $36.8 \mathrm{kcal} / \mathrm{mol}$ for $\alpha$-ROO radical. The well thus is shallower with the consequence that many barriers for product pathways are similar in energy to the entrance channel. Thus these channels will hardly be able to compete with the re-dissociation reaction. For example, the barriers for the concerted $\mathrm{HO}_{2}$ elimination reactions are $31.5 \mathrm{kcal} / \mathrm{mol}$ and $29.4 \mathrm{kcal} / \mathrm{mol}$, only about $3-5 \mathrm{kcal} / \mathrm{mol}$ lower than the entrance channel, compared to the $8 \mathrm{kcal} / \mathrm{mol}$ difference seen for the $\alpha$-ROO system. Also, the barrier for isomerization of $\beta$-ROO to $\beta \beta^{\prime}-\mathrm{QOOH}$ radical is similar to the $\beta$-ROO bond dissociation energy, making this isomerization step highly unlikely due to the high A-factor for R-OO bond scission. According to the $0 \mathrm{~K}$ energy data, the most likely product originating from the $\beta$-ROO radical PES is the bicyclic ether 2,6-dioxabicyclo[3.1.0]hexane and $\mathrm{OH}$ radical. It is formed via $\beta$-ROO radical isomerization to $\beta \alpha-\mathrm{QOOH}$ radical, followed by cyclization (intramolecular $\mathrm{OH}$ substitution). The barrier for cyclization is about $9 \mathrm{kcal} / \mathrm{mol}$ lower than the competing $\beta$-scission pathway forming 1,2-dihydrofuran and $\mathrm{HO}_{2}$.

Starting from $\beta \alpha^{\prime}-\mathrm{QOOH}$, three pathways are energetically accessible. First, $\beta$-scission of the C-C bond followed by $\mathrm{OH}$ radical elimination yields 2 -(vinyloxy)acetaldehyde. Second, the $\beta$-scission of the C-O bond proceeds through a barrier of same height and yields 4-oxo,2-hydroperoxybutyl, which either decomposes via $\beta$-scission to 2-(oxiran-2-yl)acetaldehyde and $\mathrm{OH}$ radical or to 3-butenal and $\mathrm{HO}_{2}$ radical. Third, cyclization and $\mathrm{OH}$ radical release produces 2,5-dioxabicyclo[3.1.1] hexane. Because the transition structures for these pathways vary significantly, the importance of these individual channels can only be determined from rate coefficient calculations.

\subsection{Calculated rate constants}

While all the calculated rate constants will be given in the next part, Table 1 presents the kinetic parameters calculated theoretically in the present work for the reactions shown in Figure 1, in the case where a comparison between these parameters and those derived from the recent rate rules proposed for normal alkanes by Cai et al. [20] can also be displayed. Table 1 shows that the presence of the oxygenated ring induces notable differences in rate constants at $600 \mathrm{~K}$ compared to the values obtained with the most recent 
rate rules proposed for acyclic alkanes. These differences can be as high as a factor of $10^{2.1}$ for some isomerizations (e.g. J0Ocy (CCOCC $)=$ HOOcy $(\mathrm{CCOOCC})$ ). This table also shows significant differences in the rate constants of concurrent isomerizations: the isomerizations are significantly favored, by several orders of magnitude for some relevant rate constants, when the shifted $\mathrm{H}$-atom is bonded to a carbon in an alpha position relative to 0 atom.

Table 1 : Comparison of the rate constants (in s $\mathrm{s}^{-1}$, per $\mathrm{H}$-atom basis) theoretically calculated in the present work and those obtained by the recent rate rules proposed by Cai et al. [20] in the case of the isomerizations, formation of dihydrofurans and $\mathrm{HO}_{2}$ radicals, and formations of bicyclic ethers shown in Figure 1 . The structure of the species can be found in Table S2 of Supplementary material.

\begin{tabular}{|c|c|c|c|c|}
\hline $\begin{array}{c}\text { Reaction as written in the mechanism } \\
\text { (see Table 4) }\end{array}$ & $\begin{array}{l}\text { Related rate rules } \\
\text { according Cai et al. } \\
\text { Erreur! Source du } \\
\text { renvoi introuvable. }\end{array}$ & $\begin{array}{l}\text { Rate constant at } 600 \\
\text { K from Cai et al. } \\
\text { Erreur ! Source du } \\
\text { renvoi introuvable. } \\
\text { rate rules (logk } \text { est }_{\text {est }}\end{array}$ & $\begin{array}{c}\text { Rate constant at } 600 \\
\text { K from present } \\
\text { calculations } \\
\left(\operatorname{logk}_{\text {calc }}\right)\end{array}$ & $\begin{array}{c}\log \left(\mathbf{k}_{\text {calc }} /\right. \\
\left.\mathbf{k}_{\text {est }}\right)\end{array}$ \\
\hline JOOcy(CСOCC)=HOOcy(CСJOCC) & $\begin{array}{l}\text { Alkyl peroxy radical } \\
\text { isomerization }(5\end{array}$ & -12.97 & -8.09 & 4.9 \\
\hline $\mathrm{JOOcy}(\mathrm{CCOCC})=\mathrm{HOOcy}(\mathrm{CCOCC})$ & $\begin{array}{c}\text { member ring, } \\
\text { secondary carbon } \\
\text { sites) }\end{array}$ & -12.97 & -14.72 & -1.7 \\
\hline J00су (CСOCC)=HOOcy(CСOCJC) & $\begin{array}{l}\text { Alkyl peroxy radical } \\
\text { isomerization (6 } \\
\text { member ring, } \\
\text { secondary carbon } \\
\text { sites) }\end{array}$ & -5.27 & -6.18 & -0.9 \\
\hline J00cy (COCCC $)=$ HOOcy (COCCCJ) & $\begin{array}{l}\text { Alkyl peroxy radical } \\
\text { isomerization (5 } \\
\text { member ring, } \\
\text { secondary carbon } \\
\text { sites) }\end{array}$ & -12.97 & -12.42 & 0.6 \\
\hline J0Ocy(COCCC)=HOOcy(COCCJC) & $\begin{array}{l}\text { Alkyl peroxy radical } \\
\text { isomerization }(6\end{array}$ & -5.27 & -9.70 & -4.4 \\
\hline J00су (COCCC)=HOOcy(COCJCC $)$ & $\begin{array}{c}\text { member ring, } \\
\text { secondary carbon } \\
\text { sites) }\end{array}$ & -5.27 & -4.28 & 1.0 \\
\hline $\mathrm{JOOcy}(\mathrm{CCOCC})=\operatorname{cy}\left(\mathrm{OC}^{*} \mathrm{CCC}\right)+\mathrm{HO} 2$ & Concerted & -12.60 & -13.43 & -0.8 \\
\hline $\mathrm{JOOcy}(\mathrm{CCOCC})=\operatorname{cy}\left(\mathrm{OCC}^{*} \mathrm{CC}\right)+\mathrm{HO} 2$ & eliminations & -12.60 & -11.82 & 0.8 \\
\hline $\mathrm{JOOcy}(\mathrm{COCCC})=\operatorname{cy}(\mathrm{OC} * \mathrm{CCC})+\mathrm{HO} 2$ & $\left(\mathrm{RO}_{2} \rightarrow\right.$ alkene $\left.+\mathrm{HO}_{2}\right)$ & -12.60 & -11.02 & 1.6 \\
\hline HOOcy $($ CCJOCC $)=\operatorname{cy}\left(\mathrm{OC}^{*} \mathrm{CCC}\right)+\mathrm{HO} 2$ & & -0.46 & -0.90 & -0.4 \\
\hline HOOcy $($ CСOCCJ $)=\operatorname{cy}\left(\mathrm{OCC}^{*} \mathrm{CC}\right)+\mathrm{HO} 2$ & $\mathrm{QOOH} \rightarrow$ alkene $+\mathrm{HO}_{2}$ & -0.46 & -0.06 & 0.4 \\
\hline $\mathrm{HOOcy}(\mathrm{COCCCJ})=\mathrm{cy}(\mathrm{OC} * \mathrm{CCC})+\mathrm{HO} 2$ & & -0.46 & -2.23 & -1.8 \\
\hline HOOcy (C)JOCC $)=$ bicy $(0)(\mathrm{CCCOC})+\mathrm{OH}$ & QOOH $\rightarrow$ cyclic ether + & 3.43 & 6.38 & 2.9 \\
\hline $\mathrm{HOOcy}(\mathrm{CCOCCJ})=\operatorname{bicy}(\mathrm{O})(\mathrm{CCOCC})+\mathrm{OH}$ & OH (3 member ring) & 3.43 & 3.23 & -0.2 \\
\hline
\end{tabular}

\subsection{Kinetic simulation methodology}

Simulations were performed for measurements carried out with several types of setups: a jet-stirred reactor, a rapid compression machine, a shock tube, and a low-pressure laminar flame.

\subsubsection{Jet-stirred reactor (JSR) simulations}

JSR simulations were computed using the PSR subroutine from the CHEMKIN package [19]. The target conditions were presented in the experimental studies by Vanhove et al. [8] and Dagaut et al. [6]. 


\subsubsection{Rapid-compression machine (RCM) simulations}

The RCM results of Vanhove et al. [8] were simulated using the SENKIN subroutine of the CHEMKIN package [19]. In order to take into account the compression phase and the following heat losses during RCM experiments, non-reactive time/pressure profiles were used in order to extract time/volume profiles using the isentropic law [21]. These volume profiles were used as input for the calculations. All $\mathrm{THF} / \mathrm{O}_{2} /$ inert mixtures were stoichiometric; the composition of the inert was modified in order to broaden the accessible temperature range.

\subsubsection{Shock-tube (ST) simulations}

Uygun et al. [7] measured ST ignition delays of stoichiometric THF $/ \mathrm{O}_{2} / \mathrm{N}_{2}$ mixtures with the same composition as the previously described RCM experiments [8], allowing a direct comparison of the ignition delays. The authors provided a correlation between ignition delay times and pressure:

$$
\tau_{\text {ign }}=5.26 \cdot 10^{-3} \cdot p^{-1.097} \cdot \exp \left(\frac{8096}{T}\right)
$$

where $\tau_{i g n}$ is the ignition delay given in ms, $p$ the pressure in bar and $T$ the temperature in $\mathrm{K}$. The evolution of the ignition delay with temperature was therefore calculated at three pressures corresponding to the compressed pressures at the highest observed core gas temperature in the RCM. The reported value for $d p / d t$, resulting from shock attenuation during the ignition delay was used. The simulations were performed with the SENKIN subroutine of the CHEMKIN package [19]. Uygun et al. [7] expressed concern about the occurrence of pre-ignition in the case of their experiments at the lowest temperatures: i.e., below $850 \mathrm{~K}$. The data obtained at lower temperatures were therefore not considered for the validation of the model.

\subsubsection{Flame simulations}

The above-described full mechanism was also used to compute the low-pressure laminar premixed flame results of Tran et al. [3]. This was made using the PREMIX subroutine of the CHEMKIN package [19] using the shifted average experimental temperature profile proposed by Tran et al. [3] as an input. Convergence criteria used were GRAD $=0.62$ and $\mathrm{CURV}=1$, and the presence of the low-temperature submechanism prevents convergence criteria from being refined.

\section{Kinetic model development}

The development of the kinetic model is described in the following section. It consists of a $\mathrm{C}_{0}-\mathrm{C}_{4}$ base containing the reactions consuming the secondary species formed by the oxidation of THF; a high-temperature sub-mechanism upgraded from the mechanism proposed by Tran et al. [3]; and a sub-mechanism for the low-temperature oxidation of THF, which was specifically developed for this work. The mechanism proposed by Metcalfe et al. [22] was chosen as the $\mathrm{C}_{0}-\mathrm{C}_{4}$ base. This mechanism was validated 
against a wide range of experimental data including ignition delay times obtained in rapid-compression machines and shock tubes, as well as speciation measurements in jet-stirred and flow reactors and in flames $[10,22-26]$.

\subsection{High temperature submechanism}

The high-temperature sub-mechanism proposed by Tran et al. [3] was upgraded in this work. The original mechanism was based on theoretical calculation for reactions of THF [27] and tetrahydrofuryl radicals. It was validated using the laminar-flame mole fraction profiles, ignition delay time and laminar burning velocity data. A summary of the revised rate constants used in the present study is given in Tables 2 and 3 .

Table 2 : Tetrahydrofuran reactions modified from Tran et al. work [3]. The Arrhenius parameters are given in units of $\mathrm{s}^{-1}, \mathrm{~cm}^{3}, \mathrm{~mol}^{-1}$, cal.

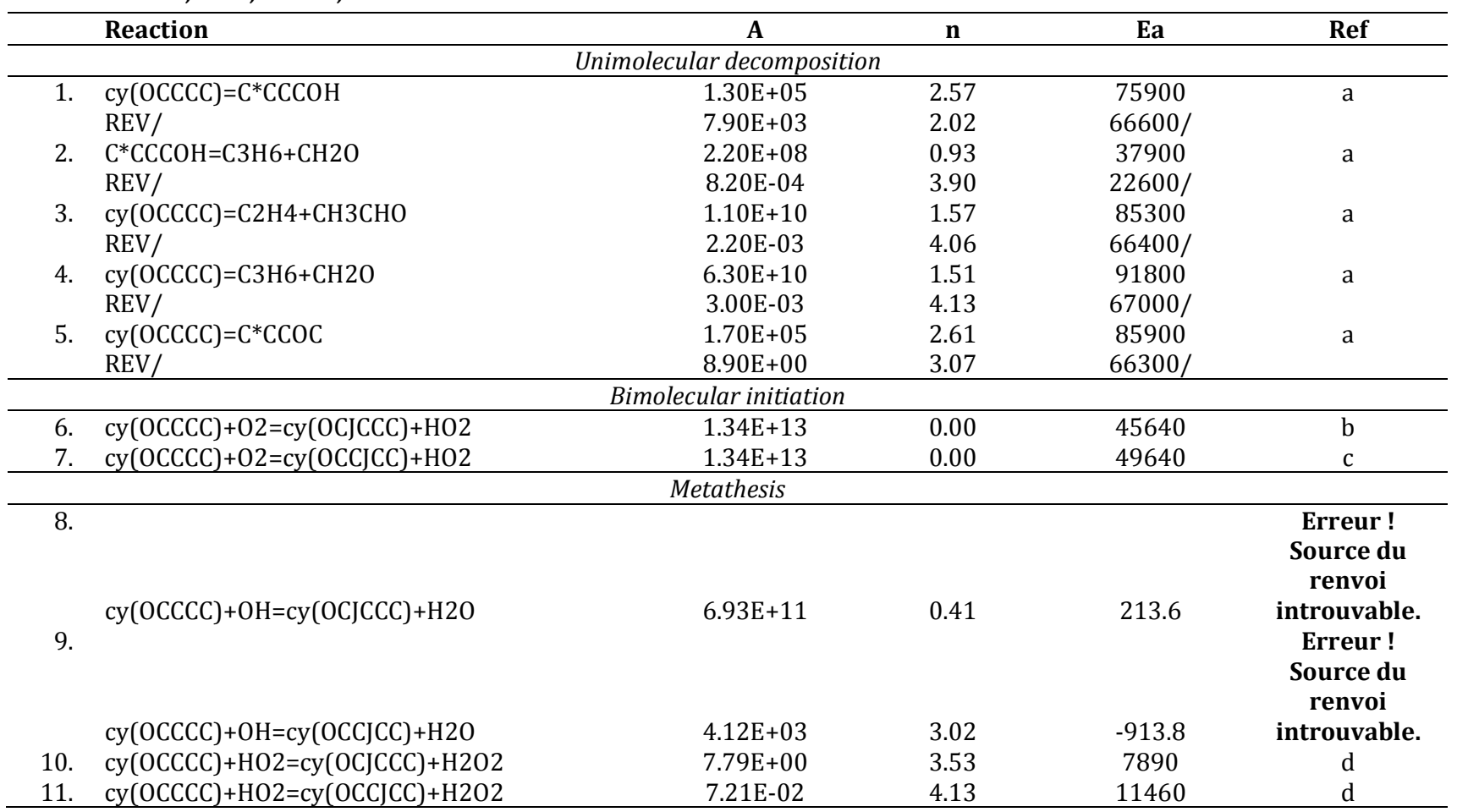

a Calculated in the present work.

b Estimated from the rate rule " $\mathrm{H}$-atom abstraction from the fuel by $\mathrm{O}_{2}$ (primary carbon sites)" [20] (activation energy $-4 \mathrm{kcal} / \mathrm{mol}$ ).

c Estimated from the rate rule " $\mathrm{H}$-atom abstraction from the fuel by $\mathrm{O}_{2}$ (primary carbon sites)" [20].

d Estimated from the rate parameters proposed by Chakravarty et al. [29] for 2-methyltetrahydrofuran and 2,5-dimethyltetrahydrofuran.

Because these reactions play a role at temperatures higher than $1200 \mathrm{~K}$, the rate parameters for the unimolecular decompositions of THF, leading to the formation of products through H-shift and ring opening, were recalculated in the present work (reactions 1-5 in Table 2). The reaction rate parameters for bimolecular initiation between THF and molecular oxygen (reactions 6 and 7) were taken as those optimized by Cai et al. [20] in the case of linear alkanes. In order to take into account the difference in $\mathrm{C}-\mathrm{H}$ bond 
dissociation energy due to the presence of an 0 -atom in an alpha location, the activation energy of reaction 6 was decreased by $4 \mathrm{kcal} / \mathrm{mol}$. The rate parameters of metatheses with $\mathrm{OH}$ radicals (reactions 8 and 9) were calculated and measured by Giri et al. [28]. However, in order to take into account the branching ratio for $\mathrm{THF}+\mathrm{OH}=$ products reactions, calculated rate parameters were used. Parameters for reactions with $\mathrm{HO}_{2}$ radicals have been proposed by Chakravarty et al. [29] for 2-methyltetrahydrofuran and 2,5-dimethyltetrahydrofuran.

Table 3 : Tetrahydrofuranyl radical reactions modified from Tran et al. work [3]. The Arrhenius parameters are given in units of $\mathrm{s}^{-1}, \mathrm{~cm}^{3}, \mathrm{~mol}^{-1}$, cal.

\begin{tabular}{|c|c|c|c|c|c|}
\hline & Reaction & A & $\mathbf{n}$ & Ea & Ref \\
\hline \multicolumn{6}{|c|}{ Isomerization } \\
\hline \multirow[t]{3}{*}{12.} & су (OCJCCC $)=\operatorname{cy}($ OCCJCC $)$ & $2.20 \mathrm{E}+08$ & 1.56 & 43800 & a \\
\hline & $\mathrm{REV} /$ & $3.10 \mathrm{E}+08$ & 1.42 & $39400 /$ & \\
\hline & DUP & & & & \\
\hline \multirow[t]{3}{*}{13.} & cy(OCJCCC $)=\operatorname{cy}($ OCCJCC $)$ & $1.30 \mathrm{E}+07$ & 1.72 & 46500 & $\mathrm{a}$ \\
\hline & REV/ & $1.90 \mathrm{E}+07$ & 1.58 & $42100 /$ & \\
\hline & DUP & & & & \\
\hline \multicolumn{6}{|c|}{ Ring opening } \\
\hline \multirow[t]{2}{*}{14.} & $\mathrm{cy}(\mathrm{OCJCCC})=\mathrm{C} 3 \mathrm{H} 6 \mathrm{CHO}-1$ & $4.50 \mathrm{E}+11$ & 0.56 & 22200 & a \\
\hline & $\mathrm{REV} /$ & $6.00 \mathrm{E}+06$ & 1.03 & $18100 /$ & \\
\hline \multirow[t]{2}{*}{15.} & $\mathrm{cy}(\mathrm{OCCJCC})=\mathrm{CH} 2 \mathrm{CHCH} 2 \mathrm{CH} 2 \mathrm{O}$ & $2.00 \mathrm{E}+12$ & 0.27 & 31100 & a \\
\hline & $\mathrm{REV} /$ & $7.00 \mathrm{E}+09$ & 0.44 & $14200 /$ & \\
\hline \multirow[t]{2}{*}{16.} & $\mathrm{CH} 2 \mathrm{CHCH} 2 \mathrm{CH} 2 \mathrm{O}=\mathrm{C} 3 \mathrm{H} 5-\mathrm{A}+\mathrm{CH} 2 \mathrm{O}$ & $2.40 \mathrm{E}+11$ & 0.58 & 6700 & a \\
\hline & $\mathrm{REV} /$ & $1.30 \mathrm{E}+03$ & 2.59 & $10700 /$ & \\
\hline \multicolumn{6}{|c|}{ H-abstraction from the tetrahydrofuryl radical } \\
\hline 17. & $\operatorname{cy}(\mathrm{OCCJCC})+\mathrm{H}=\operatorname{cy}\left(\mathrm{OCC}^{*} \mathrm{CC}\right)+\mathrm{H} 2$ & $5.00 \mathrm{E}+13$ & 0.00 & 0.0 & b \\
\hline 18. & $\mathrm{cy}(\mathrm{OCCJCC})+\mathrm{OH}=\mathrm{cy}(\mathrm{OCC} * \mathrm{CC})+\mathrm{H} 2 \mathrm{O}$ & $1.00 \mathrm{E}+13$ & 0.00 & 0.0 & b \\
\hline 19. & $\operatorname{cy}(\mathrm{OCCJCC})+0=\operatorname{cy}\left(\mathrm{OCC}^{*} \mathrm{CC}\right)+\mathrm{OH}$ & $3.00 \mathrm{E}+13$ & 0.00 & 0.0 & $\mathrm{~b}$ \\
\hline 20. & cy(OCCJCC $)+\mathrm{CH} 3=\operatorname{cy}\left(\mathrm{OCC}^{*} \mathrm{CC}\right)+\mathrm{CH} 4$ & $2.00 \mathrm{E}+12$ & 0.00 & 0.0 & b \\
\hline 21. & cy $(\mathrm{OCCJCC})+\mathrm{CH} 3 \mathrm{O}=\operatorname{cy}\left(\mathrm{OCC}^{*} \mathrm{CC}\right)+\mathrm{CH} 3 \mathrm{OH}$ & $8.00 \mathrm{E}+12$ & 0.00 & 0.0 & b \\
\hline 22. & $\operatorname{cy}(\mathrm{OCCJCC})+\mathrm{H}=\operatorname{cy}\left(\mathrm{OC}^{*} \mathrm{CCC}\right)+\mathrm{H} 2$ & $5.00 \mathrm{E}+13$ & 0.00 & 0.0 & $\mathrm{~b}$ \\
\hline 23. & $\mathrm{cy}(\mathrm{OCCJCC})+\mathrm{OH}=\mathrm{cy}\left(\mathrm{OC}^{*} \mathrm{CCC}\right)+\mathrm{H} 2 \mathrm{O}$ & $1.00 \mathrm{E}+13$ & 0.00 & 0.0 & $\mathrm{~b}$ \\
\hline 24. & $\operatorname{cy}(\mathrm{OCCJCC})+\mathrm{O}=\operatorname{cy}\left(\mathrm{OC}^{*} \mathrm{CCC}\right)+\mathrm{OH}$ & $3.00 \mathrm{E}+13$ & 0.00 & 0.0 & b \\
\hline 25. & $\operatorname{cy}(\mathrm{OCCJCC})+\mathrm{CH} 3=\operatorname{cy}\left(\mathrm{OC}^{*} \mathrm{CCC}\right)+\mathrm{CH} 4$ & $2.00 \mathrm{E}+12$ & 0.00 & 0.0 & b \\
\hline 26. & cy $(\mathrm{OCCJCC})+\mathrm{CH} 3 \mathrm{O}=\mathrm{cy}\left(\mathrm{OC}^{*} \mathrm{CCC}\right)+\mathrm{CH} 3 \mathrm{OH}$ & $8.00 \mathrm{E}+12$ & 0.00 & 0.0 & b \\
\hline 27. & $\operatorname{cy}(\mathrm{OCJCCC})+\mathrm{H}=\operatorname{cy}\left(\mathrm{OC}^{*} \mathrm{CCC}\right)+\mathrm{H} 2$ & $5.00 \mathrm{E}+13$ & 0.00 & 0.0 & $\mathrm{~b}$ \\
\hline 28. & cy $(\mathrm{OCJCCC})+\mathrm{OH}=\mathrm{cy}\left(\mathrm{OC}^{*} \mathrm{CCC}\right)+\mathrm{H} 2 \mathrm{O}$ & $1.00 \mathrm{E}+13$ & 0.00 & 0.0 & b \\
\hline 29. & $\operatorname{cy}(\mathrm{OCJCCC})+\mathrm{O}=\mathrm{cy}\left(\mathrm{OC}^{*} \mathrm{CCC}\right)+\mathrm{OH}$ & $3.00 \mathrm{E}+13$ & 0.00 & 0.0 & b \\
\hline 30. & $\mathrm{cy}(\mathrm{OCJCCC})+\mathrm{CH} 3=\operatorname{cy}\left(\mathrm{OC}^{*} \mathrm{CCC}\right)+\mathrm{CH} 4$ & $2.00 \mathrm{E}+12$ & 0.00 & 0.0 & $\mathrm{~b}$ \\
\hline 31. & $\mathrm{cy}(\mathrm{OCJCCC})+\mathrm{CH} 3 \mathrm{O}=\mathrm{cy}\left(\mathrm{OC}^{*} \mathrm{CCC}\right)+\mathrm{CH} 3 \mathrm{OH}$ & $8.00 \mathrm{E}+12$ & 0.00 & 0.0 & $\mathrm{~b}$ \\
\hline 32. & $\operatorname{cy}(\mathrm{OCJCCC})+02=\operatorname{cy}\left(\mathrm{OC}^{*} \mathrm{CCC}\right)+\mathrm{HO} 2$ & $2.00 \mathrm{E}+24$ & -3.9 & 7099.9 & $\mathrm{c}$ \\
\hline 33. & $\mathrm{cy}(\mathrm{OCCJCC})+02=\operatorname{cy}\left(\mathrm{OC}^{*} \mathrm{CCC}\right)+\mathrm{HO} 2$ & $2.00 \mathrm{E}+24$ & -3.9 & 7099.9 & $\mathrm{c}$ \\
\hline
\end{tabular}

a Calculated in the present work.

b Taken equal to the corresponding reactions of methylcyclohexanyl radical [30].

c Taken equal to the corresponding reactions as estimated by Cai et al. in the case of 2-butyltetrahydrofuran [12].

The rate parameters for the isomerization reactions 12 and 13 of Table 3 were calculated in this work. Duplicate expressions were used in the mechanism to account for the two possible pathways for these reactions. Because of their sensitivity to the reactivity of the system, the rate constants of ring-opening (reactions 14 and 15) and beta-scission (reaction 16) reactions were also calculated. Note that the rate constant for reaction 15 was reduced by a factor of 2 . This adjustment, which was within the uncertainty range of the calculations, resulted in an increase of the reactivity of the system for temperatures above $1000 \mathrm{~K}$. Rate parameters for reactions 17-31 were assumed similar to the corresponding reactions of 
methylcyclohexanyl radicals [30]. The rate constants of $\mathrm{H}$-eliminations from tetrahydrofuranyl radicals by $\mathrm{O}_{2}$ yielding $\mathrm{HO}_{2}$ radicals and dihydrofurans (reactions 32 and 33) were set as proposed by Cai et al. for 2-butyltetrahydrofuran [12], as no better approximation was found in the literature.

\subsection{Low-temperature submechanism}

A low-temperature sub-mechanism was developed during this study, using a similar structure as that usually considered for the low-temperature reaction mechanism of alkanes [31], i.e. including the oxidation pathways typically observed at temperatures between 550 and $750 \mathrm{~K}$. The main oxidation pathways are presented in Figure 2. A summary of the rate constants used here is given in Tables 4 and 5.

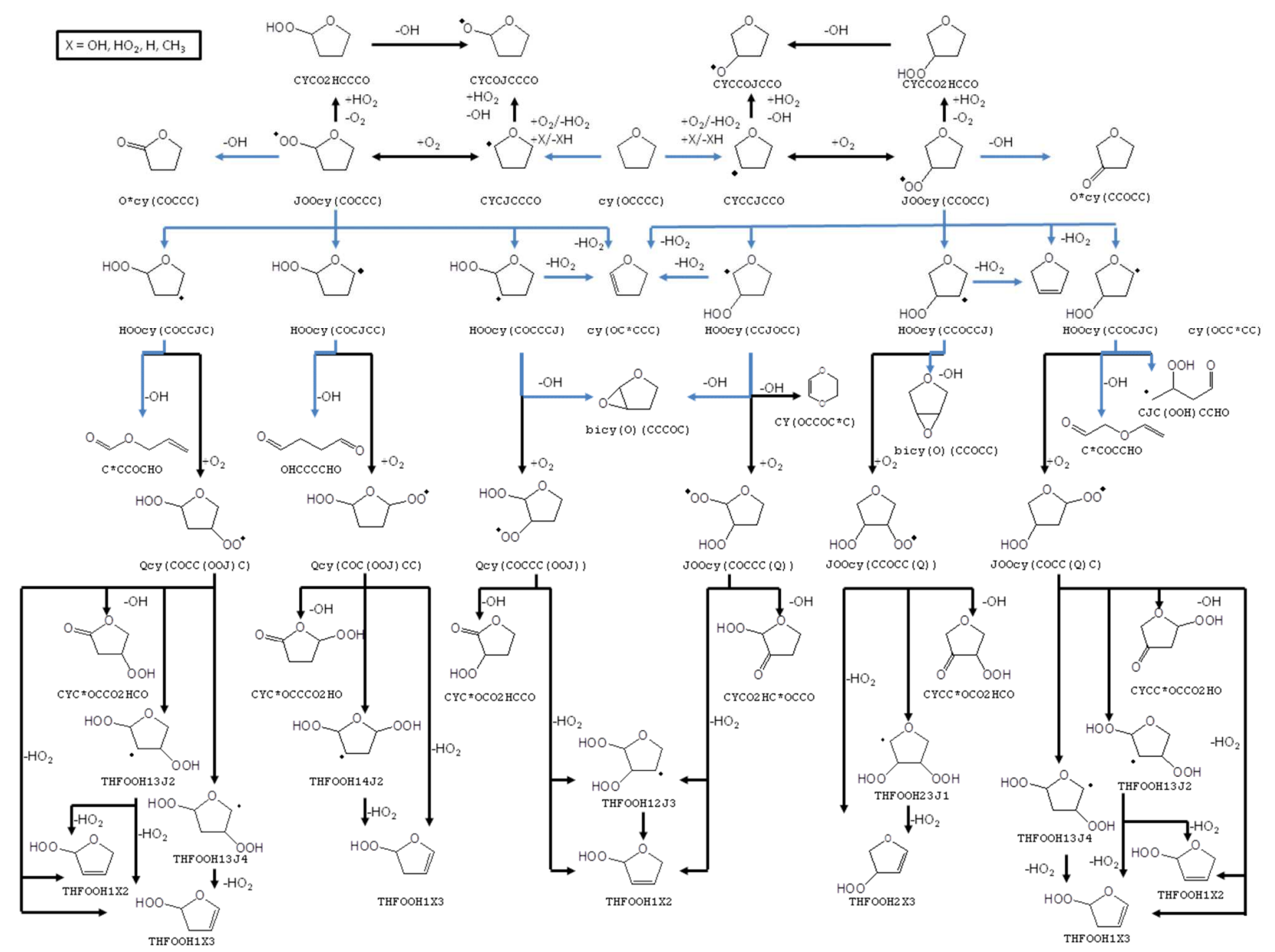

Figure 2: Main primary reaction pathways during the oxidation of THF in the low-temperature range along with species names used in the present mechanism. Blue arrows correspond to reactions with theoretically calculated rate parameters. Cyclic species nomenclature is used from Table 4, Table 5, Table 6 \& Table 7. 
Table 4: Reactions of $\mathrm{RO}_{2}$ radicals included in the low-temperature submechanism. The Arrhenius parameters are given in units of $\mathrm{s}^{-1}, \mathrm{~cm}^{3}, \mathrm{~mol}^{-1}$, cal.

\begin{tabular}{|c|c|c|c|c|c|}
\hline & Reaction & $\mathbf{A}$ & $\mathbf{n}$ & Ea & Ref \\
\hline & \multicolumn{5}{|c|}{ Addition of o $o_{2}$ to alkylradical } \\
\hline 34. & су (OCJCCC)+02=J00су (COCCC $)$ & $3.46 \mathrm{E}+14$ & -0.92 & -130 & a \\
\hline \multirow[t]{2}{*}{35.} & cy $($ OCCJCC $)+02=J 00 c y(C C O C C)$ & $1.04 \mathrm{E}+15$ & -0.92 & -130 & $\mathrm{a}$ \\
\hline & \multicolumn{5}{|c|}{ H-atom shift from alpha position } \\
\hline \multirow[t]{2}{*}{36.} & $\mathrm{JOOcy}(\mathrm{COCCC})=\mathrm{O}^{*} \operatorname{cy}(\mathrm{COCCC})+\mathrm{OH}$ & $7.40 \mathrm{E}+06$ & 1.79 & 37000 & $\mathrm{~b}$ \\
\hline & REV/ & $9.40 \mathrm{E}-01$ & 3.36 & $76100 /$ & \\
\hline \multirow[t]{3}{*}{37.} & $\mathrm{JOOcy}(\mathrm{CCOCC})=0 * \operatorname{cy}(\mathrm{CCOCC})+\mathrm{OH}$ & $1.90 \mathrm{E}+06$ & 1.99 & 38200 & b \\
\hline & REV/ & $6.80 \mathrm{E}-01$ & 3.45 & $64700 /$ & \\
\hline & \multicolumn{5}{|c|}{ H-atom shift from beta position } \\
\hline \multirow[t]{2}{*}{38.} & J00су(СОССС $)=$ HOOcy(СОССС $)$ & $1.10 \mathrm{E}+07$ & 1.57 & 28400 & $\mathrm{~b}$ \\
\hline & REV/ & $8.00 \mathrm{E}+10$ & 0.18 & $17900 /$ & \\
\hline \multirow[t]{2}{*}{39.} & J00су $($ CСOCC $)=$ HOOcy(CCJOCC $)$ & $1.80 \mathrm{E}+07$ & 1.39 & 22900 & $\mathrm{~b}$ \\
\hline & REV/ & $6.40 \mathrm{E}+08$ & 0.72 & $16900 /$ & \\
\hline \multirow[t]{3}{*}{40.} & J00су $($ CСOCC $)=$ HOOcy $($ CСOCCJ) & $1.50 \mathrm{E}+07$ & 1.57 & 31300 & $\mathrm{~b}$ \\
\hline & REV/ & $1.80 \mathrm{E}+08$ & 0.98 & $17600 /$ & \\
\hline & \multicolumn{5}{|c|}{ H-atom shift from gamma position } \\
\hline \multirow[t]{2}{*}{41.} & J00су(COCCC)=HOOcy(COCCJC) & $6.60 \mathrm{E}+06$ & 1.51 & 24700 & $\mathrm{~b}$ \\
\hline & $\mathrm{REV} /$ & $6.00 \mathrm{E}+10$ & -0.02 & $14900 /$ & \\
\hline \multirow[t]{2}{*}{42.} & J0Ocy $($ COCCC $)=$ HOOcy $(\mathrm{COCJCC})$ & $3.30 \mathrm{E}+07$ & 1.26 & 18300 & $\mathrm{~b}$ \\
\hline & REV/ & $6.40 \mathrm{E}+11$ & -0.21 & $11800 /$ & \\
\hline \multirow[t]{3}{*}{43.} & J00су $($ CСOCC $)=$ HOOcy $($ CСOCJC $)$ & $1.60 \mathrm{E}+07$ & 1.28 & 20200 & $\mathrm{~b}$ \\
\hline & REV/ & $1.50 \mathrm{E}+08$ & 0.78 & $11300 /$ & \\
\hline & \multicolumn{5}{|c|}{ Cyclic ether formation } \\
\hline \multirow[t]{2}{*}{44.} & HOOcy(COCCC) $)=$ bicy(O) $(\mathrm{CCCOC})+\mathrm{OH}$ & $2.00 \mathrm{E}+15$ & -0.57 & 13300 & $\mathrm{~b}$ \\
\hline & $\mathrm{REV} / \mathrm{C}$ & $1.40 \mathrm{E}+05$ & 2.28 & $25500 /$ & \\
\hline \multirow[t]{2}{*}{45.} & $\mathrm{HOOcy}(\mathrm{CCJOCC})=\operatorname{bicy}(0)(\mathrm{CCCOC})+\mathrm{OH}$ & $1.80 \mathrm{E}+12$ & 0.21 & 7700 & b \\
\hline & $\mathrm{REV} / \mathrm{C}$ & $4.30 \mathrm{E}+04$ & 2.37 & $22200 /$ & \\
\hline \multirow[t]{2}{*}{46.} & HOOcy $($ CСOCC $)=\operatorname{bicy}(0)($ CCOCC $)+\mathrm{OH}$ & $2.20 \mathrm{E}+11$ & 0.46 & 11200 & $\mathrm{~b}$ \\
\hline & $\mathrm{REV} /$ & $2.60 \mathrm{E}+04$ & 2.54 & $27200 /$ & \\
\hline \multicolumn{6}{|c|}{ Dioxene formation } \\
\hline 47. & HOOcy $($ CCJOCC $)=\mathrm{CY}\left(\mathrm{OCCOC}^{*} \mathrm{C}\right)+\mathrm{OH}$ & $9.0 \mathrm{E}+11$ & 0.21 & 7700 & $\mathrm{c}$ \\
\hline \multirow[t]{2}{*}{48.} & $\mathrm{HOOcy}(\mathrm{CCOCCJ})=\mathrm{CY}\left(\mathrm{OCCOC}^{*} \mathrm{C}\right)+\mathrm{OH}$ & $1.1 \mathrm{E}+11$ & 0.46 & 11200 & c \\
\hline & & & & & \\
\hline 49. & $\mathrm{HOOcy}(\mathrm{COCJCC})=\mathrm{OHCCCCHO}+\mathrm{OH}$ & $2.30 \mathrm{E}+14$ & -0.23 & 20100 & $\mathrm{~b}$ \\
\hline & $\mathrm{REV} /$ & $2.20 \mathrm{E}+01$ & 2.43 & $45700 /$ & \\
\hline 50. & $\mathrm{HOO} c y(\mathrm{CCOCJC})=\mathrm{C}^{*} \mathrm{COCCHO}+\mathrm{OH}$ & $7.00 \mathrm{E}+11$ & 0.06 & 33300 & $\mathrm{~b}$ \\
\hline & REV/ & $1.50 \mathrm{E}-01$ & 3.47 & $59900 /$ & \\
\hline 51. & $\mathrm{HOOcy}(\mathrm{COCCJC})=\mathrm{C} * \mathrm{CCOCHO}+\mathrm{OH}$ & $2.60 \mathrm{E}+11$ & 0.64 & 21800 & $\mathrm{~b}$ \\
\hline & REV/ & $2.60 \mathrm{E}+02$ & 2.12 & $36500 /$ & \\
\hline & & & & & \\
\hline 52. & $\mathrm{HOOcy}(\mathrm{COCCC})=\operatorname{cy}\left(\mathrm{OC}^{*} \mathrm{CCC}\right)+\mathrm{HO} 2$ & $1.60 \mathrm{E}+13$ & 0.12 & 18800 & $\mathrm{~b}$ \\
\hline & $\mathrm{REV} /$ & $2.20 \mathrm{E}-01$ & 3.63 & $3600 /$ & \\
\hline 53. & HOOcy $($ ССОСС $)=\operatorname{cy}($ OCC $* C)+\mathrm{HO} 2$ & $1.00 \mathrm{E}+13$ & 0.16 & 16100 & $\mathrm{~b}$ \\
\hline & $\mathrm{REV} / \mathrm{C}$ & $3.50 \mathrm{E}+02$ & 2.89 & $8100 /$ & \\
\hline 54. & HOOcy $($ CСJOCC $)=\operatorname{cy}\left(\mathrm{OC}^{*} \mathrm{CCC}\right)+\mathrm{HO} 2$ & $5.60 \mathrm{E}+13$ & -0.02 & 17400 & $\mathrm{~b}$ \\
\hline & $\mathrm{REV} /$ & $2.80 \mathrm{E}+02$ & 2.8 & $4400 /$ & \\
\hline & & & & & \\
\hline 55. & $\mathrm{JOOcy}(\mathrm{COCCC})=\operatorname{cy}\left(\mathrm{OC}^{*} \mathrm{CCC}\right)+\mathrm{HO} 2$ & $4.95 \mathrm{E}+09$ & 1.15 & 28300 & $\mathrm{~b}$ \\
\hline & $\mathrm{REV} /$ & $3.50 \mathrm{E}-01$ & 3.27 & $2630 /$ & \\
\hline 56. & $\mathrm{JOOcy}(\mathrm{CCOCC})=\operatorname{cy}(\mathrm{OC} * \mathrm{CCC})+\mathrm{HO} 2$ & $2.10 \mathrm{E}+08$ & 1.35 & 30400 & $\mathrm{~b}$ \\
\hline & $\mathrm{REV} /$ & $3.70 \mathrm{E}-02$ & 3.5 & $11500 /$ & \\
\hline 57. & $\mathrm{JOOcy}(\mathrm{CCOCC})=\operatorname{cy}(\mathrm{OCC} * \mathrm{CC})+\mathrm{HO} 2$ & $4.40 \mathrm{E}+08$ & 1.24 & 28500 & $\mathrm{~b}$ \\
\hline & $\mathrm{REV} /$ & $1.90 \mathrm{E}-01$ & 3.38 & $6700 /$ & \\
\hline
\end{tabular}

a Estimated from the rate rule "Addition of $\mathrm{O}_{2}$ to alkyl radicals (R) (secondary carbon sites)" [20].

b Calculated in the present work.

c Rate constant taken equal to that of the corresponding cyclic ether formation divided by 2 . 
Table 5 : Addition reactions of QOOH radicals to 02 and subsequent reactions. The Arrhenius parameters are given in units of $\mathrm{s}^{-1}, \mathrm{~cm}^{3}, \mathrm{~mol}^{-1}$, cal.

\begin{tabular}{|c|c|c|c|c|c|}
\hline & Reaction & A & $\mathrm{n}$ & Ea & Ref \\
\hline \multicolumn{6}{|c|}{$\mathrm{QO}_{2} \mathrm{H}$ addition to $\mathrm{O}_{2}$} \\
\hline 58. & HOOcy(COCCCJ)+O2=Qcy(COCCC(OOJ)) & $4.45 \mathrm{E}+14$ & -0.92 & -130 & a \\
\hline 59. & HOOcy $(\operatorname{COCCJC})+02=Q \operatorname{cy}(\operatorname{COCC}(00 J) C)$ & $4.45 \mathrm{E}+14$ & -0.92 & -130 & a \\
\hline 60. & HOOcy $(\mathrm{COCJCC})+02=\mathrm{Qcy}(\mathrm{COC}(\mathrm{OOJ}) \mathrm{CC})$ & $1.48 \mathrm{E}+14$ & -0.92 & -130 & $\mathrm{~b}$ \\
\hline 61. & HOOcy $($ CCJOCC $)+02=J 00 c y(\operatorname{COCCC}(Q))$ & $1.48 \mathrm{E}+14$ & -0.92 & -130 & $\mathrm{~b}$ \\
\hline 62. & HOOcy $($ CCOCCJ)+O2=J00су $(\operatorname{CCOCC}(Q))$ & $4.45 \mathrm{E}+14$ & -0.92 & -130 & a \\
\hline 63. & $\mathrm{HOOcy}(\mathrm{CCOCJC})+02=\mathrm{JOOcy}(\mathrm{COCC}(\mathrm{Q}) \mathrm{C})$ & $1.48 \mathrm{E}+14$ & -0.92 & -130 & $\mathrm{~b}$ \\
\hline \multicolumn{6}{|c|}{ Isomerization of $\mathrm{O}_{2} \mathrm{QO}_{2} \mathrm{H}$ and formation of ketohydroperoxide and $\mathrm{OH}$} \\
\hline \multirow[t]{2}{*}{64.} & $\mathrm{Qcy}(\mathrm{COCCC}(\mathrm{OOJ}))=\mathrm{CYC} * \mathrm{OCO} 2 \mathrm{HCCO}+\mathrm{OH}$ & $1.80 \mathrm{E}+07$ & 1.39 & 22900 & c \\
\hline & REV/ & $6.40 \mathrm{E}+08$ & 0.72 & $16900 /$ & \\
\hline \multirow[t]{2}{*}{65.} & $\mathrm{Qcy}(\mathrm{COCC}(\mathrm{OOJ}) \mathrm{C})=\mathrm{CYC} * \mathrm{OCCO} 2 \mathrm{HCO}+\mathrm{OH}$ & $1.60 \mathrm{E}+07$ & 1.28 & 20200 & $\mathrm{c}$ \\
\hline & REV/ & $1.50 \mathrm{E}+08$ & 0.78 & $11300 /$ & \\
\hline \multirow[t]{2}{*}{66.} & $\mathrm{Qcy}(\mathrm{COC}(\mathrm{OO}) \mathrm{JC})=\mathrm{CYC} * \mathrm{OCCCO} 2 \mathrm{HO}+\mathrm{OH}$ & $3.70 \mathrm{E}+07$ & 1.26 & 18300 & $\mathrm{c}$ \\
\hline & REV/ & $6.40 \mathrm{E}+11$ & -0.21 & $11800 /$ & \\
\hline \multirow[t]{2}{*}{67.} & $\mathrm{JOOcy}(\mathrm{COCCC}(\mathrm{Q}))=\mathrm{CYCO} 2 \mathrm{HC} * \mathrm{OCCO}+\mathrm{OH}$ & $1.10 \mathrm{E}+07$ & 1.57 & 28400 & $\mathrm{c}$ \\
\hline & $\mathrm{REV} /$ & $8.00 \mathrm{E}+10$ & 0.18 & $17900 /$ & \\
\hline \multirow[t]{2}{*}{68.} & $\mathrm{JOOcy}(\mathrm{CCOCC}(\mathrm{Q}))=\mathrm{CYCC} * \mathrm{OCO} 2 \mathrm{HCO}+\mathrm{OH}$ & $1.50 \mathrm{E}+07$ & 1.57 & 31300 & c \\
\hline & $\mathrm{REV} /$ & $1.80 \mathrm{E}+08$ & 0.98 & $17600 /$ & \\
\hline \multirow[t]{2}{*}{69.} & $\mathrm{JOOcy}(\mathrm{COCC}(\mathrm{Q}) \mathrm{C})=\mathrm{CYCC} * \mathrm{OCCO} 2 \mathrm{HO}+\mathrm{OH}$ & $6.60 \mathrm{E}+06$ & 1.51 & 24700 & $\mathrm{c}$ \\
\hline & $\mathrm{REV} /$ & $6.00 \mathrm{E}+10$ & -0.02 & $14900 /$ & \\
\hline \multicolumn{6}{|c|}{ Isomerization of $\mathrm{O}_{2} \mathrm{QO}_{2} \mathrm{H}$ forming $\mathrm{HO}_{2} \mathrm{PO}_{2} \mathrm{H}$ radical } \\
\hline \multirow[t]{6}{*}{70.} & Qсу(COC(OOJ)CC)=THFOOH14J2 & $6.60 \mathrm{E}+06$ & 1.51 & 24700 & c \\
\hline & REV/ & $6.00 \mathrm{E}+10$ & -0.02 & $14900 /$ & \\
\hline & DUP & & & & \\
\hline & $\mathrm{Qcy}(\mathrm{COC}(\mathrm{OOJ}) \mathrm{CC})=\mathrm{THFOOH} 14 \mathrm{~J} 2$ & $1.10 \mathrm{E}+07$ & 1.57 & 28400 & c \\
\hline & REV/ & $8.00 \mathrm{E}+10$ & 0.18 & $17900 /$ & \\
\hline & DUP & & & & \\
\hline \multirow[t]{2}{*}{71.} & $\mathrm{Qcy}(\mathrm{COCC}(\mathrm{OOJ}) \mathrm{C})=\mathrm{THFOOH} 13 \mathrm{~J} 2$ & $1.50 \mathrm{E}+07$ & 1.57 & 31300 & c \\
\hline & REV/ & $1.80 \mathrm{E}+08$ & 0.98 & $17600 /$ & \\
\hline \multirow[t]{2}{*}{72.} & Qcy(COCC(OOJ)C)=THFOOH13J4 & $1.80 \mathrm{E}+07$ & 1.39 & 22900 & c \\
\hline & REV/ & $6.40 \mathrm{E}+08$ & 0.72 & $16900 /$ & \\
\hline \multirow[t]{2}{*}{73.} & $\mathrm{Qcy}(\mathrm{COCCC}(\mathrm{OOJ}))=\mathrm{THFOOH} 12 \mathrm{~J} 3$ & $1.50 \mathrm{E}+07$ & 1.57 & 31300 & $\mathrm{c}$ \\
\hline & REV/ & $1.80 \mathrm{E}+08$ & 0.98 & $17600 /$ & \\
\hline \multirow[t]{2}{*}{74.} & J00су $(\operatorname{COCCC}(Q))=$ THFOOH12J3 & $6.60 \mathrm{E}+06$ & 1.51 & 24700 & $\mathrm{c}$ \\
\hline & REV/ & $6.00 \mathrm{E}+10$ & -0.02 & $14900 /$ & \\
\hline \multirow[t]{6}{*}{75.} & J00су(CCOCC(Q))=THFOOH23J1 & $3.70 \mathrm{E}+07$ & 1.26 & 18300 & c. \\
\hline & REV/ & $6.40 \mathrm{E}+11$ & -0.21 & $11800 /$ & \\
\hline & DUP & & & & \\
\hline & $\mathrm{JOOcy}(\mathrm{CCOCC}(\mathrm{Q}))=\mathrm{THFOOH} 23 \mathrm{~J} 1$ & $1.80 \mathrm{E}+07$ & 1.39 & 22900 & c \\
\hline & REV/ & $6.40 \mathrm{E}+08$ & 0.72 & $16900 /$ & \\
\hline & DUP & & & & \\
\hline \multirow[t]{2}{*}{76.} & $\mathrm{JOOcy}(\operatorname{COCC}(\mathrm{Q}) \mathrm{C})=\mathrm{THFOOH} 13 \mathrm{~J} 4$ & $3.70 \mathrm{E}+07$ & 1.26 & 18300 & $\mathrm{c}$ \\
\hline & REV/ & $6.40 \mathrm{E}+11$ & -0.21 & $11800 /$ & \\
\hline \multirow[t]{2}{*}{77.} & $\mathrm{JOOcy}(\operatorname{COCC}(\mathrm{Q}) \mathrm{C})=\mathrm{THFOOH} 13 \mathrm{~J} 2$ & $1.50 \mathrm{E}+07$ & 1.57 & 31300 & $\mathrm{c}$ \\
\hline & REV/ & $1.80 \mathrm{E}+08$ & 0.98 & $17600 /$ & \\
\hline \multirow{3}{*}{78.} & & & & & \\
\hline & THFOOH14J2=THFOOH1X3+HO2 & $1.60 \mathrm{E}+13$ & 0.12 & 18800 & $\mathrm{c}$ \\
\hline & REV/ & $2.20 \mathrm{E}-01$ & 3.63 & $3600 /$ & \\
\hline 79. & THFOOH13J2=THFOOH1X2+HO2 & $1.00 \mathrm{E}+13$ & 0.16 & 16100 & $\mathrm{c}$ \\
\hline & $\mathrm{REV} /$ & $3.50 \mathrm{E}+02$ & 2.89 & $8100 /$ & \\
\hline 80. & THFOOH13J4=THFOOH1X3+HO2 & $5.60 \mathrm{E}+13$ & -0.02 & 17400 & c \\
\hline & $\mathrm{REV} /$ & $2.80 \mathrm{E}+02$ & 2.8 & $4400 /$ & \\
\hline 81. & THFOOH12J3=THFOOH1X2+HO2 & $1.00 \mathrm{E}+13$ & 0.16 & 16100 & c \\
\hline & REV/ & $3.50 \mathrm{E}+02$ & 2.89 & $8100 /$ & \\
\hline 82. & THFOOH23J1=THFOOH2X3+HO2 & $5.60 \mathrm{E}+13$ & -0.02 & 17400 & c. \\
\hline & REV/ & $2.80 \mathrm{E}+02$ & 2.8 & $4400 /$ & \\
\hline
\end{tabular}




\begin{tabular}{|c|c|c|c|c|c|}
\hline \multirow[t]{2}{*}{83.} & $\mathrm{Qcy}(\mathrm{COC}(\mathrm{OOJ}) \mathrm{CC})=\mathrm{THFOOH} 1 \mathrm{X} 3+\mathrm{HO} 2$ & $3.30 \mathrm{E}+09$ & 1.15 & 28300 & c \\
\hline & REV/ & $3.50 \mathrm{E}-01$ & 3.27 & $2630 /$ & \\
\hline \multirow[t]{2}{*}{84.} & $\mathrm{Qcy}(\mathrm{COCC}(\mathrm{OOJ}) \mathrm{C})=\mathrm{THFOOH} 1 \mathrm{X} 3+\mathrm{HO} 2$ & $2.10 \mathrm{E}+08$ & 1.35 & 30400 & c. \\
\hline & REV/ & $3.70 \mathrm{E}-02$ & 3.5 & $11500 /$ & \\
\hline \multirow[t]{2}{*}{85.} & $\mathrm{Qcy}(\mathrm{COCC}(\mathrm{OOJ}) \mathrm{C})=\mathrm{THFOOH} 1 \mathrm{X} 2+\mathrm{HO} 2$ & $4.40 \mathrm{E}+08$ & 1.24 & 28500 & $\mathrm{c}$ \\
\hline & REV/ & $1.90 \mathrm{E}-01$ & 3.38 & $6700 /$ & \\
\hline 86. & $\begin{array}{l}\mathrm{Qcy}(\mathrm{COCCC}(\mathrm{OOJ}))=\mathrm{THFOOH} 1 \mathrm{X} 2+\mathrm{HO} 2 \\
\mathrm{REV} /\end{array}$ & $\begin{array}{l}4.40 \mathrm{E}+08 \\
1.90 \mathrm{E}-01\end{array}$ & $\begin{array}{l}1.24 \\
3.38\end{array}$ & $\begin{array}{l}28500 \\
6700 /\end{array}$ & c \\
\hline 87. & $\begin{array}{l}\text { JOOcy }(\text { CCOCC }(Q))=\text { THFOOH } 2 \text { X3+HO2 } \\
\text { REV } /\end{array}$ & $\begin{array}{l}2.10 \mathrm{E}+08 \\
3.70 \mathrm{E}-02\end{array}$ & $\begin{array}{c}1.35 \\
3.5\end{array}$ & $\begin{array}{c}30400 \\
11500 /\end{array}$ & c \\
\hline 88. & $\begin{array}{l}\text { JOOcy }(\mathrm{COCC}(\mathrm{Q}) \mathrm{C})=\mathrm{THFOOH} 2 \mathrm{X} 3+\mathrm{HO} 2 \\
\text { REV/ }\end{array}$ & $\begin{array}{l}3.30 \mathrm{E}+09 \\
3.50 \mathrm{E}-01\end{array}$ & $\begin{array}{l}1.15 \\
3.27\end{array}$ & $\begin{array}{l}28300 \\
2630 /\end{array}$ & c \\
\hline \multicolumn{6}{|c|}{ Decompostion of dihydrofuranyl hydroperoxides } \\
\hline 89. & THFOOH1X3=HCO+C*CCHO+OH & $3.87 \mathrm{E}+21$ & -1.82 & 44588.5 & $\mathrm{~d}$ \\
\hline 90. & $\mathrm{THFOOH} 1 \mathrm{X} 2=\mathrm{HCO}+\mathrm{C} * \mathrm{CCHO}+\mathrm{OH}$ & $3.87 \mathrm{E}+21$ & -1.82 & 44588.5 & $\mathrm{~d}$ \\
\hline 91. & $\mathrm{THFOOH} 2 \mathrm{X} 3=\mathrm{HCO}+\mathrm{C} * \mathrm{CCHO}+\mathrm{OH}$ & $3.87 \mathrm{E}+21$ & -1.82 & 44588.5 & $\mathrm{~d}$ \\
\hline \multicolumn{6}{|c|}{ Decomposition of ketohydroperoxides } \\
\hline 92. & CYC*OCO2HCCO=products $+\mathrm{OH}$ & $3.87 \mathrm{E}+21$ & -1.82 & 44588.5 & $\mathrm{~d}$ \\
\hline 93. & $\mathrm{CYC} * \mathrm{OCCO} 2 \mathrm{HCO}=$ products $+\mathrm{OH}$ & $3.87 \mathrm{E}+21$ & -1.82 & 44588.5 & $\mathrm{~d}$ \\
\hline 94. & $\mathrm{CYC}^{*} \mathrm{OCCCO} 2 \mathrm{HO}=$ products $+\mathrm{OH}$ & $3.87 \mathrm{E}+21$ & -1.82 & 44588.5 & $\mathrm{~d}$ \\
\hline 95. & $\mathrm{CYCO} 2 \mathrm{HC} * \mathrm{OCCO}=$ products $+\mathrm{OH}$ & $3.87 E+21$ & -1.82 & 44588.5 & $\mathrm{~d}$ \\
\hline 96. & $\mathrm{CYCC}^{*} \mathrm{OCO} 2 \mathrm{HCO}=$ products $+\mathrm{OH}$ & $3.87 \mathrm{E}+21$ & -1.82 & 44588.5 & $\mathrm{~d}$ \\
\hline 97. & $\mathrm{CYCC}^{*} \mathrm{OCCO} 2 \mathrm{HO}=$ products $+\mathrm{OH}$ & $3.87 \mathrm{E}+21$ & -1.82 & 44588.5 & $\mathrm{~d}$ \\
\hline
\end{tabular}

a Estimated from the rate rule "Addition of 02 to QOOH (secondary carbon sites)" [20].

b Estimated from the rate rule "Addition of 02 to QOOH (secondary carbon sites) with A-factor/3.

c Rate constants taken equal to those calculated for the same type of reaction in Table 4.

d Rate parameters taken equal to those calculated by Goldsmith et al. [32] for the decomposition of the ketohydroperoxides formed during the low temperature oxidation of propane.

Table 4 describes the first $\mathrm{O}_{2}$ addition and the subsequent reactions. Reactions 34 and 35, in Table 4, describe the addition of tetrahydrofuranyl radicals on $\mathrm{O}_{2}$ molecules. The reaction rate parameters were taken as optimized by Cai et al. [8] for alkanes. In the case of the addition of tetrahydrofuranyl radical with the radical carbon adjacent to the oxygen atom, the rate constant was reduced by a factor of 3 . This is in line with the work of Tripathi et al. about the oxidation of 2-methylTHF [11] considering that formed adducts are less stable due to the weak bonding at these sites. The rate parameters of the subsequent reactions, 36-46, and 49-57, were calculated in this work. These reactions include isomerization reactions of $\mathrm{RO}_{2}$ radicals into $\mathrm{QOOH}$ radicals, cyclic ether formation from QOOH radicals, ring opening of QOOH radicals by beta-scission, and two classes of reactions forming the unsaturated counterparts of THF, 2,3-dihydrofuran and 2,5-dihydrofuran, by concerted elimination of an $\mathrm{HO}_{2}$ radical from the $\mathrm{RO}_{2}$ radicals and an $\mathrm{HO}_{2}$ radical loss from $\mathrm{QOOH}$ radicals.

The A factor of the ring-opening reaction 49, yielding butanedial, was reduced by a factor of 1.5 . Due to the importance of dioxene formation during JSR oxidation contrasting to bicyclic ethers not being observed [8], reactions 47 and 48 assuming a more complex rearrangement during the decomposition of hydroperoxy radicals were added with rate constants based on those calculated for cyclic ether formation. The kinetic influence of these reactions on reactivity and other product formation is negligible. Note that after a more thorough investigation of the mass spectrum reported by Vanhove et al. [8], dioxene has been identified as being mostly 1,3-dioxene.

Table 5 describes the second $\mathrm{O}_{2}$ addition and the subsequent reactions. Only the channels leading to hydroperoxide types detected by Antonov et al. [9] were taken into account. Cai et al. [20] reported optimized 
reaction rates for the addition of $\mathrm{QOOH}$ radicals to $\mathrm{O}_{2}$. These values were used in this work. However, the rate constants were set three times lower in the case of an addition on the radical site in the alpha position of the oxygen atom. For the other reactions of Table 5, the rate constants used were those calculated for reactions presented in Table 4, for suitable cases. Goldsmith et al. [32] calculated decomposition rate constants of the ketohydroperoxides formed during the low temperature oxidation of propane. These rate parameters were used in this study for reactions 92 to 97 . The same rate parameters were used for the decomposition of dihydrofuranyl hydroperoxides (reactions 89-91).

The $\mathrm{H}$-abstraction reactions from bicyclic ethers are presented in Table 6. For H-atom abstraction by $\mathrm{H}$-atoms and $\mathrm{CH}_{3}$ and $\mathrm{HO}_{2}$ radicals (reactions 98-103 and 104-116), the rate parameters were calculated in the present work. For $\mathrm{H}$-atom abstractions by $\mathrm{OH}$ radical (reactions 104 and 117), they were taken from the study on 2-methylTHF from Tripathi et al. [11].

Table 6: Reactions of bicyclic ethers. The Arrhenius parameters are given in units of $\mathrm{s}^{-1}, \mathrm{~cm}^{3}, \mathrm{~mol}^{-1}$, cal.

\begin{tabular}{|c|c|c|c|c|c|}
\hline & Reaction & $\mathbf{A}$ & $\mathbf{n}$ & Ea & Ref \\
\hline \multicolumn{6}{|c|}{ Bicyclic ether reactions } \\
\hline 98. & $\operatorname{bicy}(0)(\mathrm{CCCOC})+\mathrm{H}=>\mathrm{H} 2+\operatorname{bicy}(0)(\mathrm{CCJOCC})$ & $7.00 \mathrm{E}+06$ & 2.24 & 4500 & $\mathrm{a}$ \\
\hline 99. & bicy $(0)(\mathrm{CCCOC})+\mathrm{H}=>\mathrm{H} 2+\operatorname{bicy}(0)(\mathrm{CCJCOC})$ & $5.20 \mathrm{E}+07$ & 1.96 & 11400 & a \\
\hline 100. & bicy $(0)(\mathrm{CCCOC})+\mathrm{CH} 3=>\mathrm{CH} 4+\operatorname{bicy}(\mathrm{O})(\mathrm{CCCJOC})$ & $8.70 \mathrm{E}+02$ & 3.08 & 7300 & a \\
\hline 101. & bicy $(0)(\mathrm{CCCOC})+\mathrm{CH} 3=>\mathrm{CH} 4+\operatorname{bicy}(0)(\mathrm{CCJCOC})$ & $1.50 \mathrm{E}+03$ & 2.94 & 11700 & a \\
\hline 102. & $\operatorname{bicy}(0)(\mathrm{CCCOC})+\mathrm{HO} 2=>\mathrm{H} 2 \mathrm{O} 2+\operatorname{bicy}(\mathrm{O})(\mathrm{CCCJOC})$ & $6.70 \mathrm{E}+00$ & 3.67 & 9200 & a \\
\hline 103. & $\operatorname{bicy}(0)(\mathrm{CCCOC})+\mathrm{HO} 2=>\mathrm{H} 2 \mathrm{O} 2+\operatorname{bicy}(\mathrm{O})(\mathrm{CCJCOC})$ & $1.20 \mathrm{E}+03$ & 3.12 & 18400 & a \\
\hline 104. & $\operatorname{bicy}(0)(\mathrm{CCCOC})+\mathrm{OH}=>\mathrm{H} 2 \mathrm{O}+\operatorname{bicy}(\mathrm{O})(\mathrm{CC}) \mathrm{COC})$ & $6.06 \mathrm{E}+12$ & 0.0 & 0 & $\mathrm{~b}$ \\
\hline 105. & $\operatorname{bicy}(0)($ CCOCC $)+\mathrm{H}=>\mathrm{H} 2+\operatorname{bicy}(0)($ C $J O C C)$ & $2.90 \mathrm{E}+07$ & 1.97 & 13500 & $\mathrm{a}$ \\
\hline 106. & $\operatorname{bicy}(0)($ CCOCC $)+\mathrm{H}=>\mathrm{H} 2+\operatorname{bicy}(0)(\mathrm{CJCOCC})$ & $2.40 \mathrm{E}+07$ & 1.98 & 10900 & a \\
\hline 107. & $\operatorname{bicy}(0)($ CCOCC $)+\mathrm{H}=>\mathrm{H} 2+\operatorname{bicy}(0)($ CCOCCJ $)$ & $9.80 \mathrm{E}+06$ & 2.12 & 7200 & $\mathrm{a}$ \\
\hline 108. & $\operatorname{bicy}(0)(\mathrm{CCOCC})+\mathrm{H}=>\mathrm{H} 2+\operatorname{bicy}(0)(\mathrm{CCOCJC})$ & $9.50 \mathrm{E}+06$ & 2.15 & 5900 & $\mathrm{a}$ \\
\hline 109. & $\operatorname{bicy}(\mathrm{O})(\mathrm{CCOCC})+\mathrm{CH} 3=>\mathrm{CH} 4+\operatorname{bicy}(\mathrm{O})(\mathrm{CC} \mathrm{OCC})$ & $8.10 \mathrm{E}+02$ & 2.94 & 13000 & $\mathrm{a}$ \\
\hline 110. & bicy $(0)(\mathrm{CCOCC})+\mathrm{CH} 3=>\mathrm{CH} 4+\operatorname{bicy}(\mathrm{O})(\mathrm{CJCOCC})$ & $6.60 \mathrm{E}+02$ & 2.96 & 11400 & a \\
\hline 111. & bicy $(0)(\mathrm{CCOCC})+\mathrm{CH} 3=>\mathrm{CH} 4+\operatorname{bicy}(\mathrm{O})(\mathrm{CCOCCJ})$ & $5.20 \mathrm{E}+02$ & 3.03 & 8900 & a \\
\hline 112. & bicy $(0)(\mathrm{CCOCC})+\mathrm{CH} 3=>\mathrm{CH} 4+\operatorname{bicy}(0)(\mathrm{CCOCJC})$ & $1.40 \mathrm{E}+02$ & 3.22 & 7900 & $\mathrm{a}$ \\
\hline 113. & $\operatorname{bicy}(0)(\mathrm{CCOCC})+\mathrm{HO} 2=>\mathrm{H} 2 \mathrm{O} 2+\operatorname{bicy}(0)(\mathrm{CCJOCC})$ & $2.80 \mathrm{E}+02$ & 3.25 & 21400 & a \\
\hline 114. & $\operatorname{bicy}(0)(\mathrm{CCOCC})+\mathrm{HO} 2=>\mathrm{H} 2 \mathrm{O} 2+\operatorname{bicy}(\mathrm{O})(\mathrm{CJCOCC})$ & $5.70 \mathrm{E}+02$ & 3.17 & 17700 & a \\
\hline 115. & $\operatorname{bicy}(0)(\mathrm{CCOCC})+\mathrm{HO} 2=>\mathrm{H} 2 \mathrm{O} 2+\operatorname{bicy}(0)(\mathrm{CCOCC})$ & $1.00 \mathrm{E}+01$ & 3.31 & 13900 & a \\
\hline 116. & $\operatorname{bicy}(0)(\mathrm{CCOCC})+\mathrm{HO} 2=>\mathrm{H} 2 \mathrm{O} 2+\operatorname{bicy}(0)(\mathrm{CCOCJC})$ & $4.80 \mathrm{E}-02$ & 4.24 & 9900 & a \\
\hline 117. & $\operatorname{bicy}(0)(\mathrm{CCOCC})+\mathrm{OH}=>\mathrm{H} 2 \mathrm{O}+\operatorname{bicy}(0)(\mathrm{CC} J O C C)$ & $6.06 \mathrm{E}+12$ & 0.0 & 0 & $\mathrm{~b}$ \\
\hline
\end{tabular}

a Calculated in the present work.

b Taken equal to the corresponding reactions of methylTHF [11].

The resulting radicals, bicy $(0)(\mathrm{CCJOCC})$ and bicy $(0)(\mathrm{CCJCOC})$ radicals, are assumed to decompose rapidly to give oxirane and ketenyl radicals and acrolein and HCO radicals, respectively.

Table 7 summarizes the rate parameters chosen for the reactions of formation and consumption of tetrahydrofuranyloxy radicals (reactions 118-137). These radicals can decompose into ethylene, formaldehyde and HCO radical. These reactions are known to have an impact on the overall reactivity of the oxidation system in the low-temperature range [33]. The rate parameters for reactions 118-135 were taken from the work of Tripathi et al. [11], while those of reactions 136-137 were calculated in this study. 
Table 7 : Reactions producing and consuming tetrahydrofuranyloxy radicals. The Arrhenius parameters are given in units of $\mathrm{s}^{-1}, \mathrm{~cm}^{3}, \mathrm{~mol}^{-1}$, cal.

\begin{tabular}{|c|c|c|c|c|c|}
\hline & Reaction & $\mathbf{A}$ & $\mathbf{n}$ & Ea & Ref \\
\hline \multicolumn{6}{|c|}{$\mathrm{R}+\mathrm{HO}_{2}<=>\mathrm{RO}+\mathrm{OH}$} \\
\hline 118. & $\mathrm{cy}(\mathrm{OCJCCC})+\mathrm{HO} 2=\mathrm{CYCOJCCCO}+\mathrm{OH}$ & $4.89 \mathrm{E}+12$ & 0.00 & -1000 & $\mathrm{a}$ \\
\hline 119. & $\mathrm{cy}(\mathrm{OCCJCC})+\mathrm{HO} 2=\mathrm{CYCCOJCCO}+\mathrm{OH}$ & $4.89 \mathrm{E}+12$ & 0.00 & -1000 & $\mathrm{a}$ \\
\hline \multicolumn{6}{|c|}{$\mathrm{R}+\mathrm{CH}_{3} \mathrm{O}_{2}<=>\mathrm{RO}+\mathrm{CH}_{3} \mathrm{O}$} \\
\hline \multirow[t]{2}{*}{120.} & $\mathrm{cy}(\mathrm{OCJCCC})+\mathrm{CH} 3 \mathrm{O} 2=\mathrm{CYCOJCCCO}+\mathrm{CH} 3 \mathrm{O}$ & $7.00 \mathrm{E}+12$ & 0.00 & -1000 & a \\
\hline & $\mathrm{cy}(\mathrm{OCCJCC})+\mathrm{CH} 3 \mathrm{O} 2=\mathrm{CYCCOJCCO}+\mathrm{CH} 3 \mathrm{O}$ & $7.00 \mathrm{E}+12$ & 0.00 & -1000 & $\mathrm{a}$ \\
\hline \multicolumn{6}{|c|}{$R O_{2}+R=R O+R O$} \\
\hline 121. & J00су (COCCC $)+$ су (OCJCCC $)=$ CYCOJCCCO+CYCOJCCCO & $7.00 \mathrm{E}+12$ & 0.00 & -1000 & a \\
\hline 122 & JOOcy $($ COCСC $)+\operatorname{cy}($ OCCJCC $)=$ CYCOJCCCO+CYCCOJCCO & $7.00 \mathrm{E}+12$ & 0.00 & -1000 & a \\
\hline 123. & $\mathrm{JOOcy}(\mathrm{CCOCC})+\mathrm{cy}(\mathrm{OCJCCC})=\mathrm{CYCOJCCCO}+\mathrm{CYCCOJCCO}$ & $7.00 \mathrm{E}+12$ & 0.00 & -1000 & a \\
\hline 124. & $\mathrm{JOOcy}(\mathrm{CCOCC})+\mathrm{cy}(\mathrm{OCCJCC})=\mathrm{CYCCOJCCO}+\mathrm{CYCCOJCCO}$ & $7.00 \mathrm{E}+12$ & 0.00 & -1000 & a \\
\hline \multicolumn{6}{|c|}{$\mathrm{ROO}+\mathrm{HO}_{2}=\mathrm{ROOH}+\mathrm{O}_{2}$} \\
\hline 125. & $\mathrm{JOOcy}(\mathrm{COCCC})+\mathrm{HO} 2=\mathrm{CYCO} 2 \mathrm{HCCCO}+02$ & $1.75 \mathrm{E}+10$ & 0.00 & -3275 & a \\
\hline 126. & $\mathrm{JOOcy}(\mathrm{CCOCC})+\mathrm{HO} 2=\mathrm{CYCO} 2 \mathrm{HCCCO}+02$ & $1.75 \mathrm{E}+10$ & 0.00 & -3275 & $\mathrm{a}$ \\
\hline \multicolumn{6}{|c|}{$\mathrm{ROO}+\mathrm{H}_{2} \mathrm{O}_{2}<=>\mathrm{ROOH}+\mathrm{HO}_{2}$} \\
\hline 127. & $\mathrm{JOOcy}(\mathrm{COCCC})+\mathrm{H} 2 \mathrm{O} 2=\mathrm{CYCO} 2 \mathrm{HCCCO}+\mathrm{HO} 2$ & $2.40 \mathrm{E}+12$ & 0.00 & 10000 & $\mathrm{a}$ \\
\hline 128. & $\mathrm{JOOcy}(\mathrm{CCOCC})+\mathrm{H} 2 \mathrm{O} 2=\mathrm{CYCO} 2 \mathrm{HCCCO}+\mathrm{HO} 2$ & $2.40 \mathrm{E}+12$ & 0.00 & 10000 & $\mathrm{a}$ \\
\hline \multicolumn{6}{|c|}{$\mathrm{RO}_{2}+\mathrm{CH}_{3} \mathrm{O}_{2}<=>\mathrm{RO}+\mathrm{CH}_{3} \mathrm{O}+\mathrm{O}_{2}$} \\
\hline 129. & $\mathrm{J00cy}(\mathrm{COCCC})+\mathrm{CH} 3 \mathrm{O} 2=>\mathrm{CYCOJCCCO}+\mathrm{CH} 3 \mathrm{O}+\mathrm{O} 2$ & $1.40 \mathrm{E}+16$ & -1.61 & 1860 & a \\
\hline 130. & $\mathrm{JOOcy}(\mathrm{CCOCC})+\mathrm{CH} 3 \mathrm{O} 2=>\mathrm{CYCCOJCCO}+\mathrm{CH} 3 \mathrm{O}+\mathrm{O} 2$ & $1.40 \mathrm{E}+16$ & -1.61 & 1860 & a \\
\hline \multicolumn{6}{|c|}{$\mathrm{RO}_{2}+\mathrm{RO}_{2}<=>\mathrm{RO}+\mathrm{RO}+\mathrm{O}_{2}$} \\
\hline 131. & $\mathrm{JOOcy}(\mathrm{COCCC})+\mathrm{JOOcy}(\mathrm{COCCC})=\mathrm{CYCOJCCCO}+\mathrm{CYCOJCCCO}+\mathrm{O} 2$ & $1.40 \mathrm{E}+16$ & -1.61 & 1860 & a \\
\hline 132. & $\mathrm{JOOcy}(\mathrm{COCCC})+\mathrm{JOOcy}(\mathrm{CCOCC})=\mathrm{CYCOJCCCO}+\mathrm{CYCCOJCCO}+\mathrm{O} 2$ & $1.40 \mathrm{E}+16$ & -1.61 & 1860 & a \\
\hline 133. & $\mathrm{JOOcy}(\mathrm{CCOCC})+\mathrm{JOO} c y(\mathrm{CCOCC})=\mathrm{CYCCOJCCO}+\mathrm{CYCCOJCCO}+02$ & $1.40 \mathrm{E}+16$ & -1.61 & 1860 & $\mathrm{a}$ \\
\hline \multicolumn{6}{|c|}{$\mathrm{RO}_{2} \mathrm{H}<=>\mathrm{RO}+\mathrm{OH}$} \\
\hline 134. & CYCO2HCCCO=CYCOJCCCO $+\mathrm{OH}$ & $1.00 \mathrm{E}+16$ & 0.00 & 39000 & $\mathrm{a}$ \\
\hline 135. & $\mathrm{CYCO} 2 \mathrm{HCCCO}=\mathrm{CYCCOJCCO}+\mathrm{OH}$ & $1.00 \mathrm{E}+16$ & 0.00 & 39000 & $\mathrm{a}$ \\
\hline \multicolumn{6}{|c|}{ Alkyloxy radical decomposition } \\
\hline 136. & $\mathrm{CYCOJCCCO}=\mathrm{C} 2 \mathrm{H} 4+\mathrm{CH} 2 \mathrm{O}+\mathrm{HCO}$ & $4.40 \mathrm{E}+12$ & 0.38 & 9400 & $\mathrm{~b}$ \\
\hline 137. & $\mathrm{CYCCOJCCO}=\mathrm{C} 2 \mathrm{H} 4+\mathrm{CH} 2 \mathrm{O}+\mathrm{HCO}$ & $1.40 \mathrm{E}+12$ & 0.45 & 20000 & $\mathrm{~b}$ \\
\hline
\end{tabular}

a Rate constants taken equal to those proposed by Tripathi et al. [11] for the same type of reaction.

b Calculated in the present work.

The species formed in the previously described reactions can also react in the low to intermediate temperature range, and recent updates in their oxidation under these temperature conditions were included in the mechanism. Butanal-4-yl (C3H6CHO-1) radical is an abundant low-temperature oxidation product of THF obtained by ring opening of the 1-tetrahydrofuranyl radical [34], and it can easily isomerize into a butanal-1-yl radical. It was therefore necessary for the mechanism to include the subsequent reactions of the addition of butanal-4-yl or butanal-1-yl radicals to $\mathrm{O}_{2}$. The reactivities of these two radicals were studied by Veloo et al. [35] in their work on the low-temperature oxidation of butanal and were used here.

The present model contains 467 species and 2390 reactions. Thermodynamic properties of the species added in comparison to the work of Tran et al. [3] were calculated as explained in the previous section. This model together with the respective thermodynamic and transport data are provided in CHEMKIN format as supplementary material. 


\section{Model validations and discussion}

The performance of the model has been evaluated using the following experimental data from literature in the temperature range relevant to low and high temperature combustion chemistry (500-2200 K):

- Quantification of combustion intermediates in JSRs both close to atmospheric pressure at temperatures ranging from 500 to $1100 \mathrm{~K}$, [8], and at a pressure of $1.023 \mathrm{MPa}$ at temperatures ranging from 800 to $1120 \mathrm{~K}$ [6].

- First-stage and ignition delay measurements as well as identification of low-temperature intermediates in a RCM [8]. The RCM-simulated conditions spanned adiabatic core gas temperatures from 640 to $890 \mathrm{~K}$ and pressures after compression from 0.64 to $0.91 \mathrm{MPa}$.

- Ignition delay measurements in a shock tube [7] at pressures equal to $0.64,0.77$ and $0.91 \mathrm{MPa}$ and temperatures for the simulations ranging from 831 to $1105 \mathrm{~K}$.

- The structure of laminar premixed low-pressure (6.7 $\mathrm{kPa})$, argon-diluted $(78 \%)$ stoichiometric THF flames [3].

Because the JSR data at $0.1023 \mathrm{MPa}$ above $800 \mathrm{~K}$ [6] and in flames [3] mainly involve high-temperature oxidation, the validations against these relevant experimental data are presented in the supplementary material (see Figures S2 and S3). The agreement for the JSR results is satisfactory. The agreement for the flame results is comparable, even slightly better in some cases than that of Tran et al. [3].

\subsection{Low-temperature jet-stirred reactor data}

The experimental data obtained in a JSR by Vanhove et al. [8] were simulated using the current model for temperatures between 500 and $1100 \mathrm{~K}$ and at equivalence ratios $0.5,1$, and 2 . The model predictions are presented in Figures 3-6. The temperature profile and mole fraction profiles of the 24 reported species were simulated. To discuss the important pathways, a reaction flow analysis of the THF oxidation in a JSR at $600 \mathrm{~K}$ is presented in Figure 7.

As shown in Figure 3, simulated THF mole fraction profiles reflect the experimentally observed trends, with the low-temperature reactivity starting at $550 \mathrm{~K}$, and the maximal THF conversion observed at $600 \mathrm{~K}$. At this temperature, as depicted in Figure $7,73.2 \%$ of THF is converted into the cy(CJOCCC) radical (2-tetrahydrofuranyl radical) because of the lower $\mathrm{C}-\mathrm{H}$ bond dissociation energy in the carbon next to the oxygen atom. The formation of this radical is favored, with a branching ratio between the 2- vs. 3-tetrahydrofuranyl radicals close to 3:1. The simulations show that more than $90 \%$ of THF is converted by $\mathrm{H}$-atom abstraction by $\mathrm{OH}$ radical. Less than $10 \%$ of $\mathrm{THF}$ consumption can be attributed to $\mathrm{H}$-atom abstraction reactions by $\mathrm{HO}_{2}$ radical at this temperature. An adjustment of the branching ratio between $\mathrm{QOOH}$ radical decomposition and $\mathrm{QOOH}$ radical addition to $\mathrm{O}_{2}$ could improve the agreement for JSR reactivity around $600 \mathrm{~K}$, but to the detriment of the prediction of RCM data. 

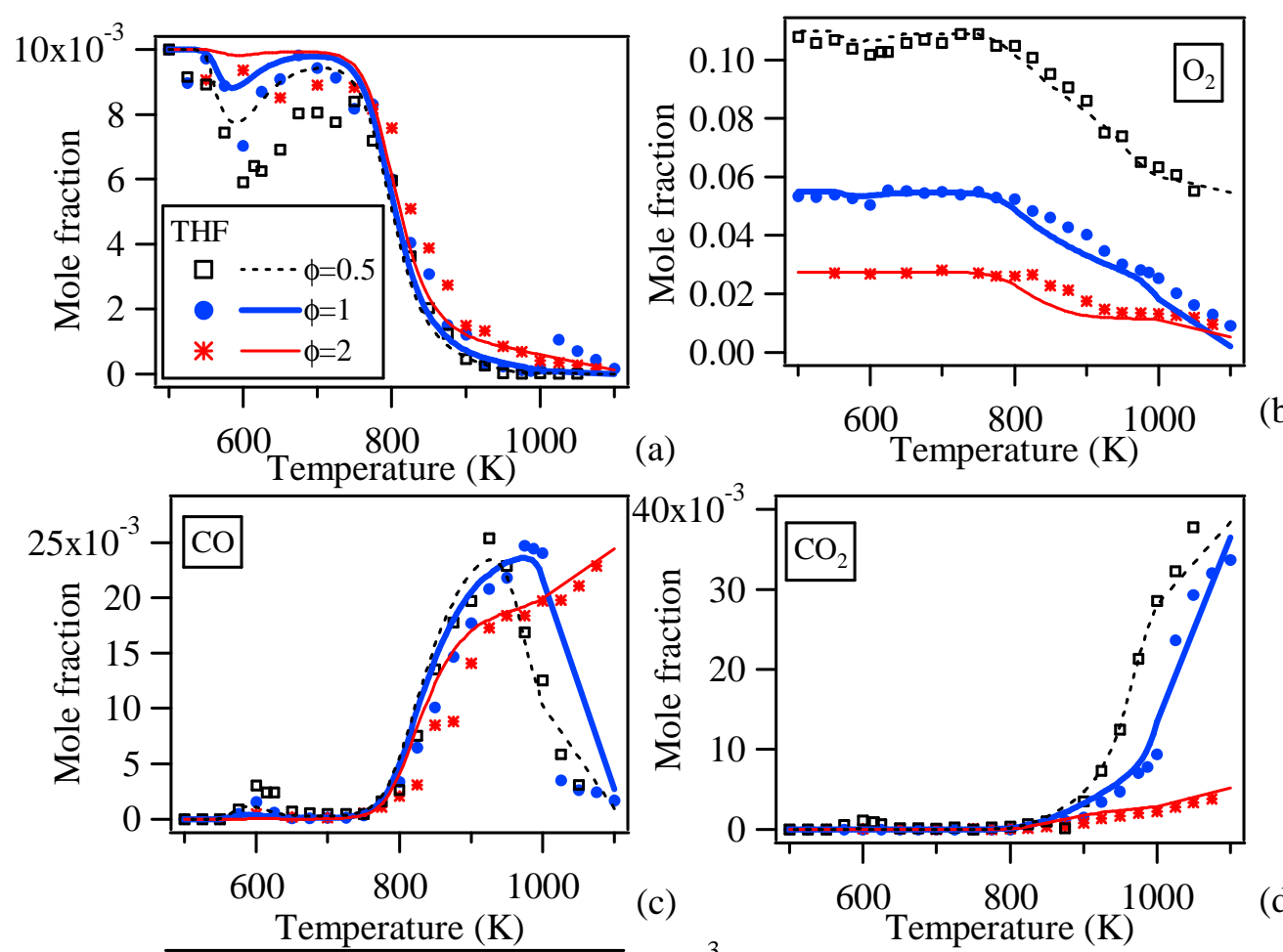

(b)

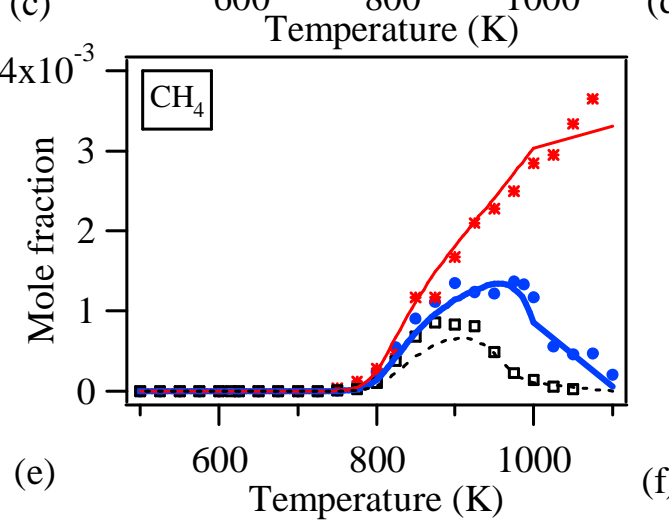

Figure 3 : Comparison between simulated (lines) and experimental (symbols) [8] mole fraction profiles for the reactants, and major products observed during the oxidation of THF $/ \mathrm{O}_{2} / \mathrm{He}$ mixtures in a JSR at $\mathrm{p}=0.106 \mathrm{MPa}, \tau=2 \mathrm{~s}$ and $\phi$ from 0.5 to 2 .

The reactions of 2-tetrahydrofuranyl radical leading to the formation of ketohydroperoxides are significant pathways under these conditions and contribute to the rise of reactivity by the release of two $\mathrm{OH}$ radicals. Nevertheless, the major reaction pathway from 2-tetrahydrofuranyl radical leads to the formation of the stable intermediate, butanedial (OHCCCCHO). The internal isomerization of tetrahydrofuranylperoxy radicals is significantly favored when the shifted $\mathrm{H}$-atom is bonded to a carbon in alpha position to $\mathrm{O}$ atom because of the reduced bond dissociation energy of the $\mathrm{C}-\mathrm{H}$ bond. Butanedial has been observed in large quantities in the RCM speciation experiments, but not in the JSR experiments [8]. Antonov et al. [9] also mentioned this compound as the major product observed during their THF oxidation study. The predicted conversion of THF in the low temperature range is underestimated, especially at $\phi=0.5$. The isomerization 
of 2-tetrahydrofuranylperoxy radicals with the shifted $\mathrm{H}$-atom bonded to a carbon in beta position to $\mathrm{O}$ atom is a source of allylformate, a product also seen in RCM but not in JSR experiments [8]. The reaction pathways yielding butanedial and allylformate result in a global decrease of the overall reactivity of the system, as they are in competition with ketohydroperoxide formation pathways.

As is shown in Figure 3, $\mathrm{CO}$ and $\mathrm{CO}_{2}$ mole fraction profiles are well predicted, except in the low-temperature reactivity region, where the experimental mole fraction of $\mathrm{CO}$ of several thousands of ppm is notably underestimated. This underprediction is connected to the reactivity underestimation in the same temperature range. It could also be explained by missing secondary pathways leading to the formation of small oxygenated compounds such as oxirane or propanal, which are also significantly underpredicted as noticed in Figure 5. A sensitivity analysis on the $\mathrm{CO}$ mole fraction under the conditions of Figure 3 is presented in Figure S4 of Supplementary Material. The influential reactions are the same as what will be discussed further in the text for RCM first-stage ignition delay time. This made it difficult to improve the agreement for JSR results without deteriorating it for RCM data. Figure 5 also shows that the predicted mole fraction profiles of formaldehyde, acetaldehyde, and 2-propenal are globally in good agreement with the experimental data, nevertheless with an underestimation of $\mathrm{CH}_{2} \mathrm{O}$ mole fraction by a factor of 2 between 550 and $650 \mathrm{~K}$.

In the low temperature reactivity regime, no $\mathrm{H}_{2}$ or $\mathrm{CH}_{4}$ formation (see Figure 3 ) is predicted by the model, in accordance with the experiments. This result suggests that at these temperatures, $\mathrm{H}$-abstractions from THF by $\mathrm{H}$ atoms and methyl radicals are not effective. This is confirmed by the reaction-flux analysis at $600 \mathrm{~K}$, which shows that the radicals active in $\mathrm{H}$-abstractions are mainly $\mathrm{OH}$ and $\mathrm{HO}_{2}$ radicals.

Figure 4 demonstrates that the mole fraction profiles of $\mathrm{C}_{2}$ - $\mathrm{C}_{3}$ hydrocarbons, $\mathrm{CH}_{4}, \mathrm{C}_{2} \mathrm{H}_{6}, \mathrm{C}_{2} \mathrm{H}_{4}, \mathrm{C}_{2} \mathrm{H}_{2}, \mathrm{C}_{3} \mathrm{H}_{6}$ and $\mathrm{C}_{3} \mathrm{H}_{8}$ are fairly well predicted. Propene was measured for temperatures higher than $600 \mathrm{~K}$, with a maximum at $800 \mathrm{~K}$. At $600 \mathrm{~K}$, as shown in Figure 7, it is mostly formed by the sequence cy(CJOCCC) $\rightarrow$ butan-1-al-4-yl $\rightarrow n-\mathrm{C}_{3} \mathrm{H}_{7}(+\mathrm{CO}) \rightarrow n-\mathrm{C}_{3} \mathrm{H}_{7} \mathrm{O}_{2} \rightarrow \mathrm{C}_{3} \mathrm{H}_{6}\left(+\mathrm{HO}_{2}\right)$. This sequence remains the main formation pathway of propene even at higher temperatures. The reactions from butan-1-al-4-yl radicals are the most important source of ethylene at $600 \mathrm{~K}$. Figure 4 shows that the predicted mole fractions of $\mathrm{C}_{4}$ hydrocarbons are underpredicted by a factor of 2 for 1-butene and more for 1,3-butadiene.

Figure 6 demonstrates that the predicted mole fraction profiles of the cyclic products formed during THF oxidation are in good agreement with the experimental data in all the temperature range. This is especially the case of the unsaturated counterparts of THF, 2,3-dihydrofuran $\left(\mathrm{cy}\left(\mathrm{OC}^{*} \mathrm{CCC}\right)\right.$ ) and 2,5-dihydrofuran (cy $\left(\mathrm{OCC}^{*} \mathrm{CC}\right)$ ). At $600 \mathrm{~K}$, dihydrofurans are mainly produced by concerted elimination reactions: JOOcy $(\mathrm{COCCC})<=>\operatorname{cy}\left(\mathrm{OC}^{*} \mathrm{CCC}\right)+\mathrm{HO}_{2}$ for $(2,3)$-dihydrofuran and JOOcy $(\mathrm{CCOCC})<=>\operatorname{cy}\left(\mathrm{OCC}^{*} \mathrm{CC}\right)+\mathrm{HO}_{2}$ for 2,5-dihydrofuran at $600 \mathrm{~K}$. $\mathrm{H}$-abstraction reactions by $\mathrm{O}_{2}$ from tetrahydrofuranyl radicals are the most effective way to form 2,3-dihydrofuran. The model is also able to predict the mole fraction profile of furan well. Cyclopropanecarboxaldehyde is mostly formed by the isomerization of 2,3-dihydrofuran [36]. Its mole fraction profile is therefore also fairly well reproduced in the simulations. Even based on rough assumptions, the reactions added for dioxene formation (see Table 4) lead to a good prediction of the mole fraction of this cyclic species. Except for dihydrofurans, dioxene is the most important experimentally detected product deriving from 3-tetrahydrofuranyl radical. 


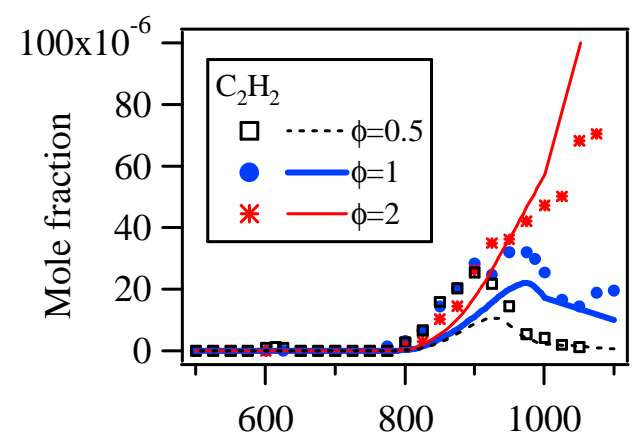

Temperature (K)

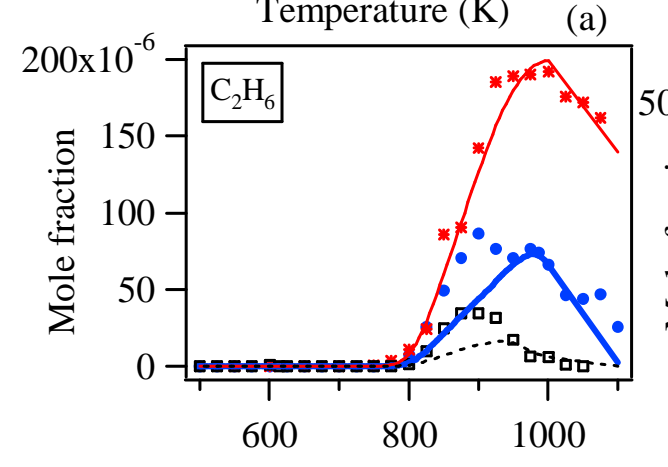

Temperature $(\mathrm{K})$

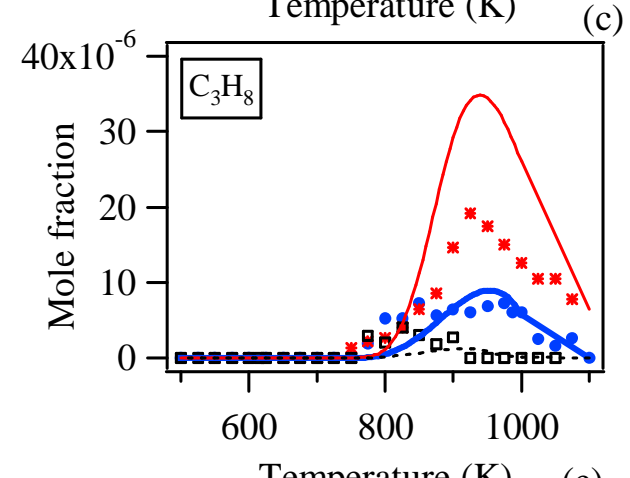

Temperature (K)

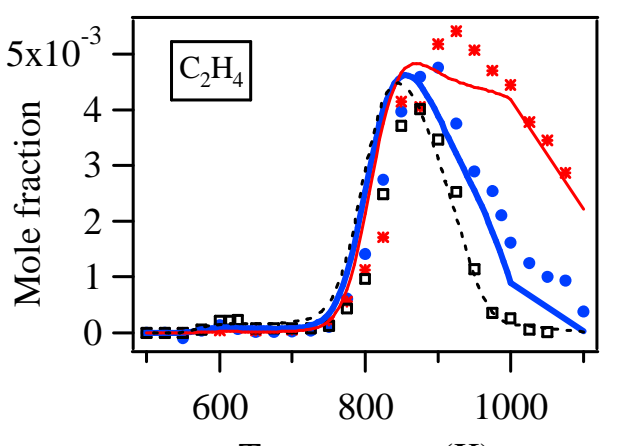

Temperature (K)

(b)

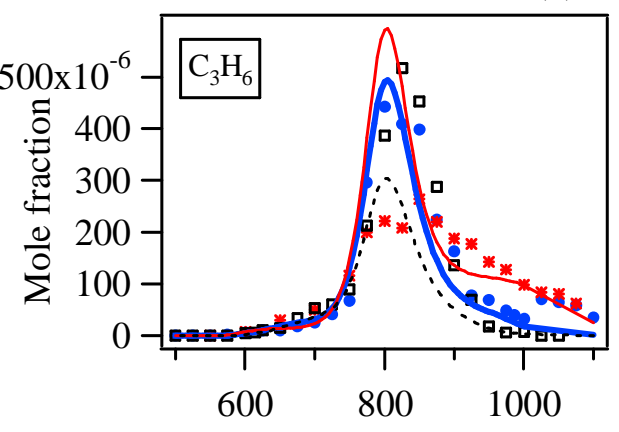

Temperature (K)

(d)

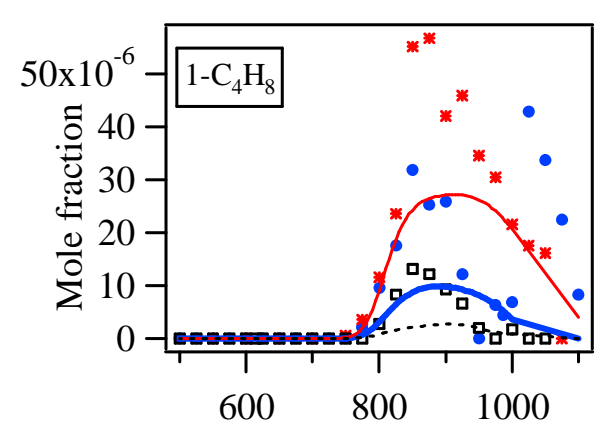

Temperature (K)

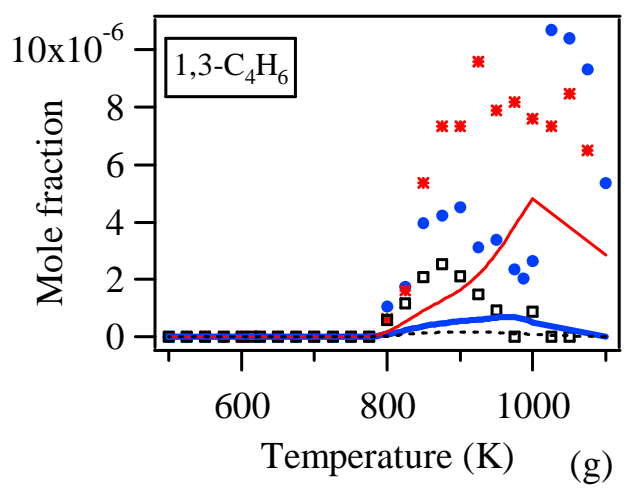

Figure 4 : Comparison between simulated (lines) and experimental (symbols) [8] mole fraction profiles for the hydrocarbons produced during the oxidation of THF $/ \mathrm{O}_{2} / \mathrm{He}$ mixtures in a JSR at $\mathrm{p}=0.106 \mathrm{MPa}, \tau=2 \mathrm{~s}$ and $\phi$ from 0.5 to 2 . 

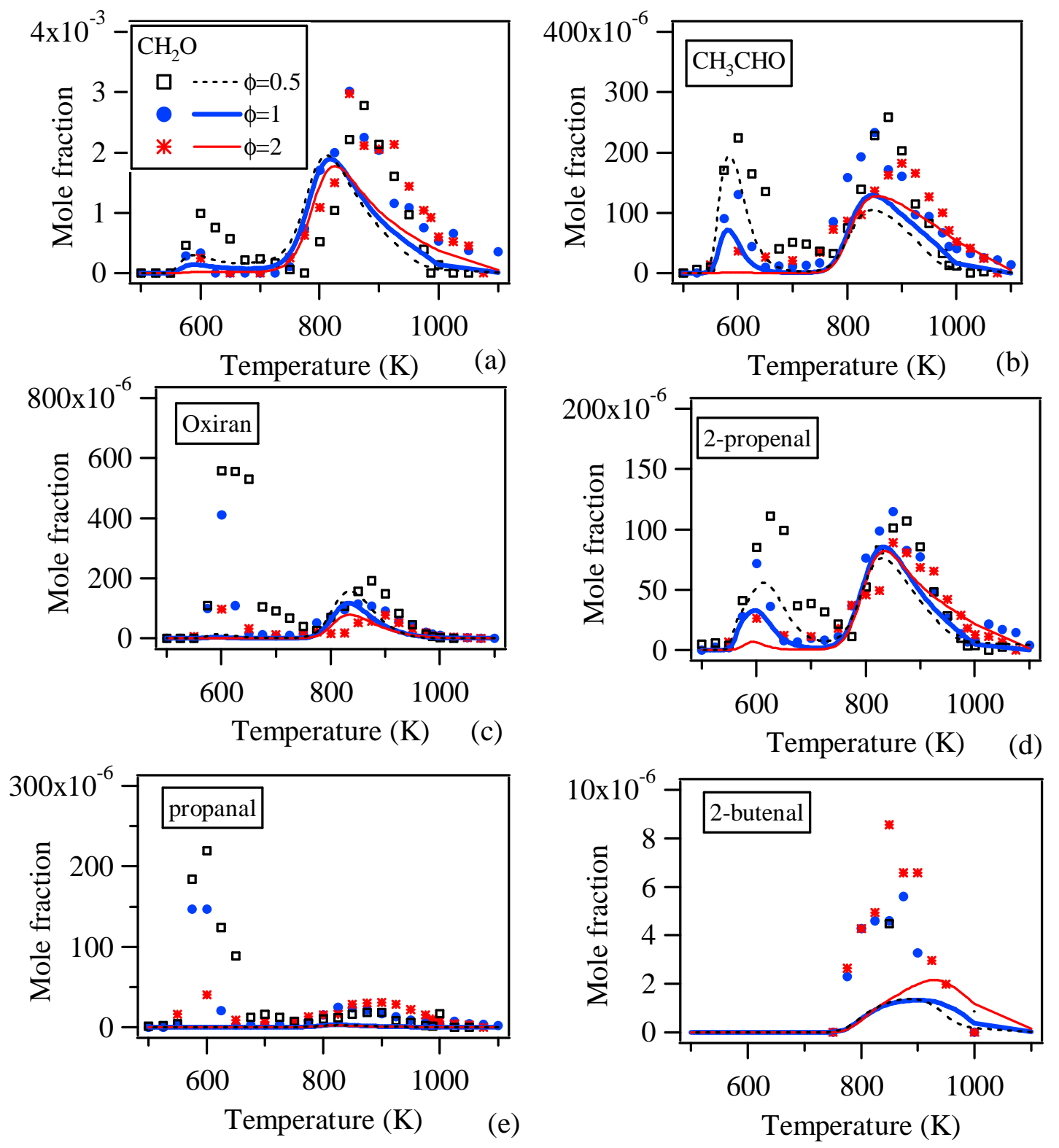

(f)

Figure 5 : Comparison between simulated (lines) and experimental (symbols) [8] mole fraction profiles for the acyclic oxygenated compounds produced during the oxidation of THF $/ \mathrm{O}_{2} / \mathrm{He}$ mixtures in a JSR at $\mathrm{p}=0.106 \mathrm{MPa}, \tau=2 \mathrm{~s}$ and $\phi$ from 0.5 to 2 . 

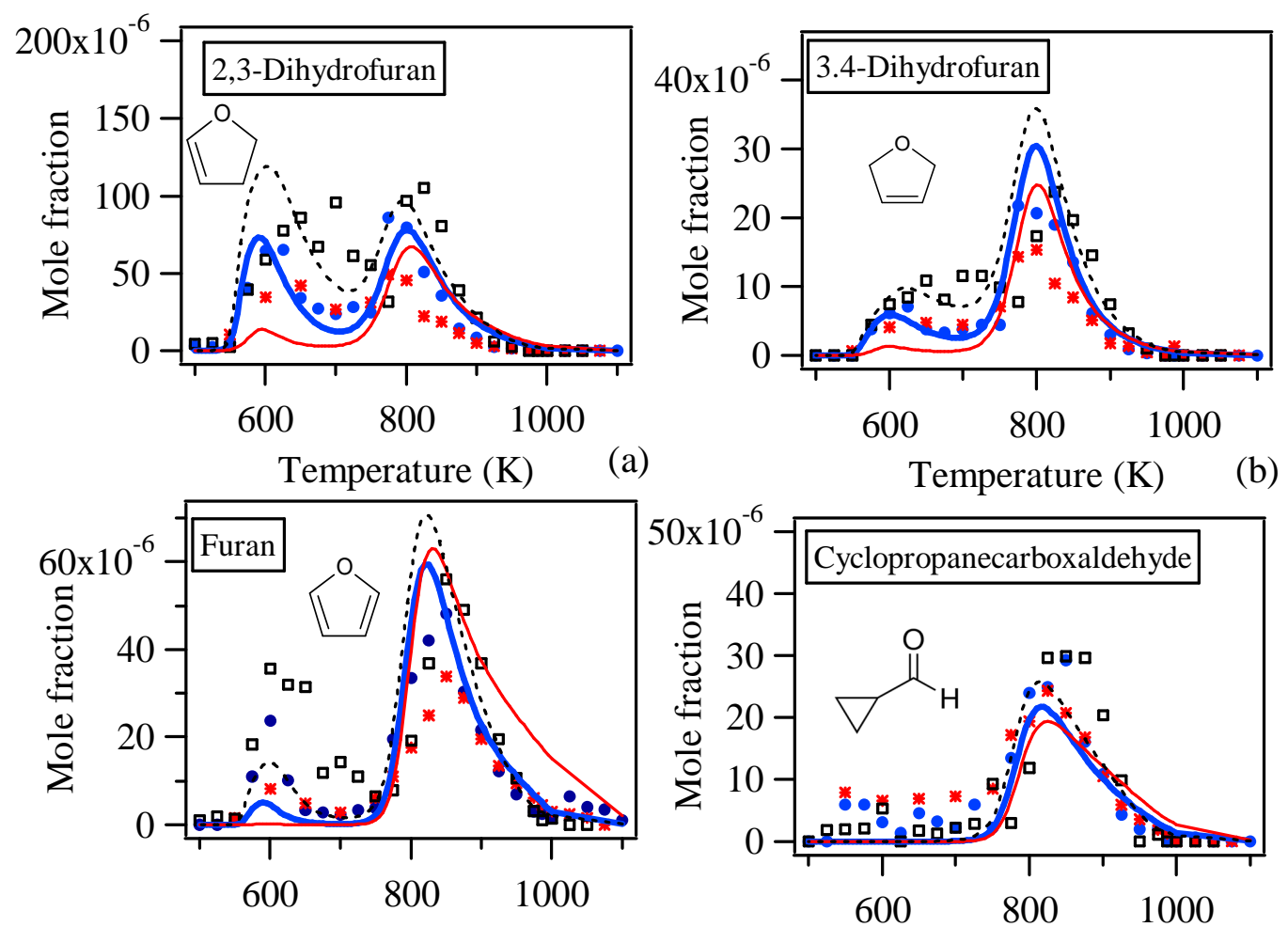

Temperature (K)

(c)
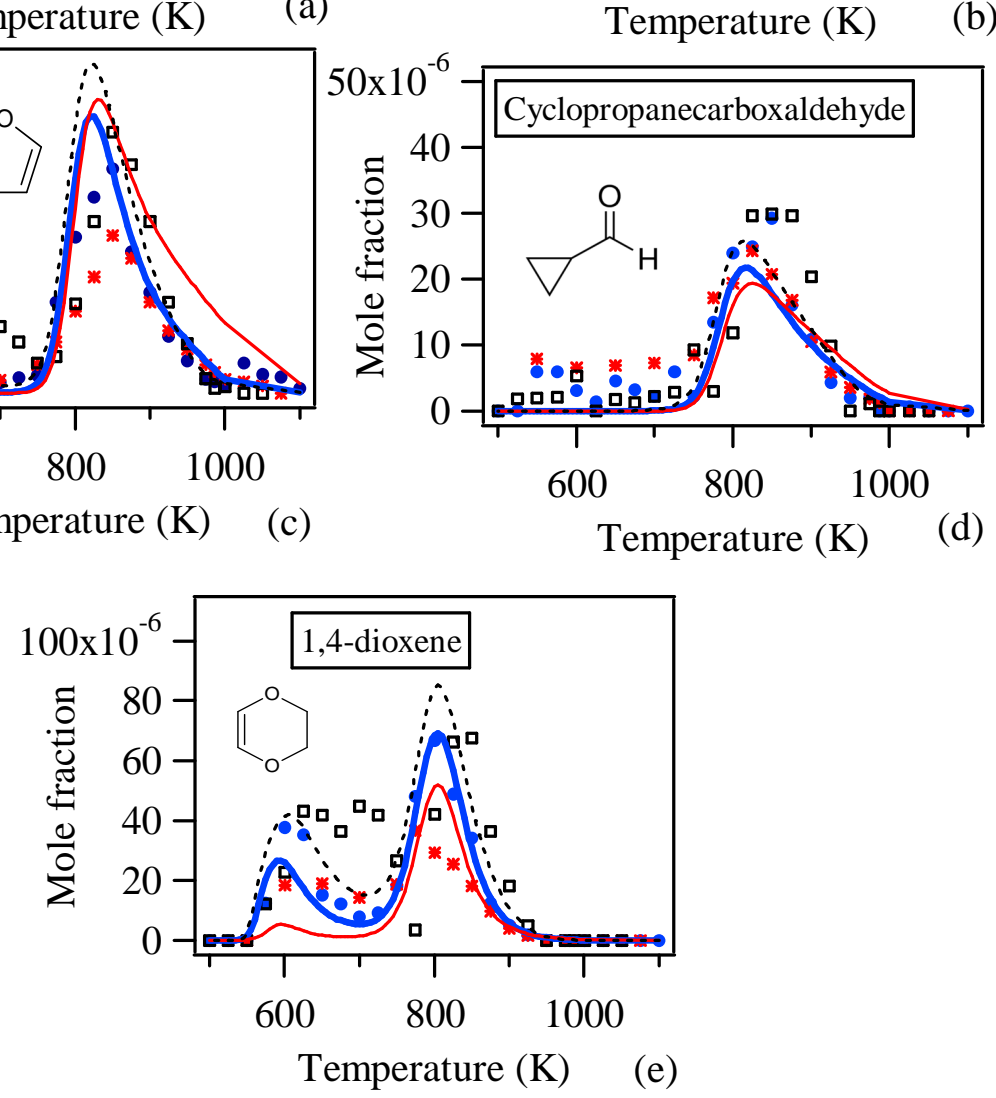

Figure 6 : Comparison between simulated (lines) and experimental (symbols) [8] mole fraction profiles for the cyclic oxygenated compounds produced during the oxidation of THF $/ \mathrm{O}_{2} / \mathrm{He}$ mixtures in a JSR at $\mathrm{p}=0.106 \mathrm{MPa}, \tau=2 \mathrm{~s}$ and $\phi$ from 0.5 to 2 . 


\subsection{Ignition delay times}

Figure 8 presents performance assessment of the current model concerning ignition delay times in a RCM and in a ST.

Under RCM conditions of pressures at top dead center ( $\mathrm{p}_{\mathrm{TDC}}$ ) from 0.53 to $0.91 \mathrm{MPa}$, the experimental temperature evolution of ignition delay times exhibits a deviation from Arrhenius behavior, and two-stage ignition is observed for temperatures below $720 \mathrm{~K}$. Globally, the simulations demonstrate accurate prediction of this non-Arrhenius behavior, with ignition delay times in fair agreement with the experimental data. The first-stage ignition delay times are also well predicted by the model. Nevertheless, the ignition delays are underestimated by the model in the temperature range $720-800 \mathrm{~K}$.

Under shock-tube conditions at similar pressure conditions vs. the RCM, agreement between simulations and experiments is good. Overestimation of the ignition delay times is $30 \%$ in the least favorable case, around $900 \mathrm{~K}$ when the pressure increases.

In order to highlight the important reactions involved during THF auto-ignition, a brute-force sensitivity analysis was performed on both first-stage (when applicable) and total ignition delays. The results of the brute-force analysis on the first stage and total ignition delays are displayed in Figure 9 for conditions relevant to both RCM and shock-tube experiments.

In Figure 9, the sensitivity coefficient for total ignition delay time of a reaction i is defined as: $\sigma_{\mathrm{i}}=\log \left(\tau_{\mathrm{i}^{+}}{ }^{+} \tau_{\mathrm{i}^{-}}{ }^{-}\right)$ / $(\log (2.0 / 0.5))$, where $\tau_{\mathrm{i}}{ }^{+}$is the total ignition delay calculated with a factor-of-two increase in the reactionrate coefficient of reaction $\mathrm{i}\left(\mathrm{k}_{\mathrm{i}}\right)$, and $\tau_{\mathrm{i}}^{-}$is the ignition delay calculated with a factor-of-two decrease in $\mathrm{k}_{\mathrm{i}}$. The sensitivity coefficient for first-stage ignition delay time is calculated with the same process, changing total ignition delays by first-stage ignition delays. A positive $\sigma_{i}$ indicates an overall inhibiting effect on reactivity, and vice versa.

Figure 9a shows that the sequence of reactions displayed in Figure 10 is of particular importance in promoting the reactivity during the first stage ignition. The $\mathrm{C}-\mathrm{H}$ bond dissociation energy is lowered by the presence of an oxygen atom next to the radical carbon, therefore favoring $\mathrm{H}$-abstraction reactions forming 2-tetrahydrofuranyl radical (cy(OCJCCC)) from THF and the H-shift in the case of isomerization reactions between $\mathrm{RO}_{2}$ and $\mathrm{QOOH}$ radicals. The reactions consuming radicals formed in this sequence thereby inhibit the overall reactivity and exhibit a positive sensitivity coefficient. It is the case for reactions HOOcy(COCJCC) $=\mathrm{OHCCCCHO}+\mathrm{OH}, \mathrm{cy}(\mathrm{OCJCCC})+\mathrm{O}_{2}=\mathrm{cy}\left(\mathrm{OC}^{*} \mathrm{CCC}\right)+\mathrm{HO}_{2}$ and $\mathrm{JOOcy}(\mathrm{COCCC})=\mathrm{cy}\left(\mathrm{OC}^{*} \mathrm{CCC}\right)+\mathrm{HO}_{2}$, which moreover yield stable oxidation intermediates.

Reactions forming 3-tetrahydrofuranyl radical also inhibit reactivity. This is partly due to the stable intermediates formed by the reaction of this radical, namely dihydrofurans, dioxene and cyclopropane carboxaldehyde (see Figure 7), and to the increased difficulty of undergoing internal isomerization to a ketohydroperoxide in the case of the corresponding 1-peroxy-3-hydroperoxidetetrahydrofuranyl radical (J00cy $(\operatorname{COCC}(\mathrm{Q}) \mathrm{C}))$. The rate constant at $600 \mathrm{~K}$ is $\mathrm{k}_{\mathrm{keto600 \textrm {K }}}=10^{2.02} \mathrm{~s}^{-1}$. This latter radical is more likely to lead to the formation of dihydrofuranperoxide by a concerted elimination of a $\mathrm{HO}_{2}$ radical $\left(\mathrm{k}_{\mathrm{elim}} 600 \mathrm{~K}=10^{2.4} \mathrm{~s}^{-1}\right)$ as 
shown in Figure 11. According to Figure 7, in JSR, at $600 \mathrm{~K}, 98 \%$ of J00cy(COCC(Q)C radicals are consumed by $\mathrm{HO}_{2}$ radical elimination.
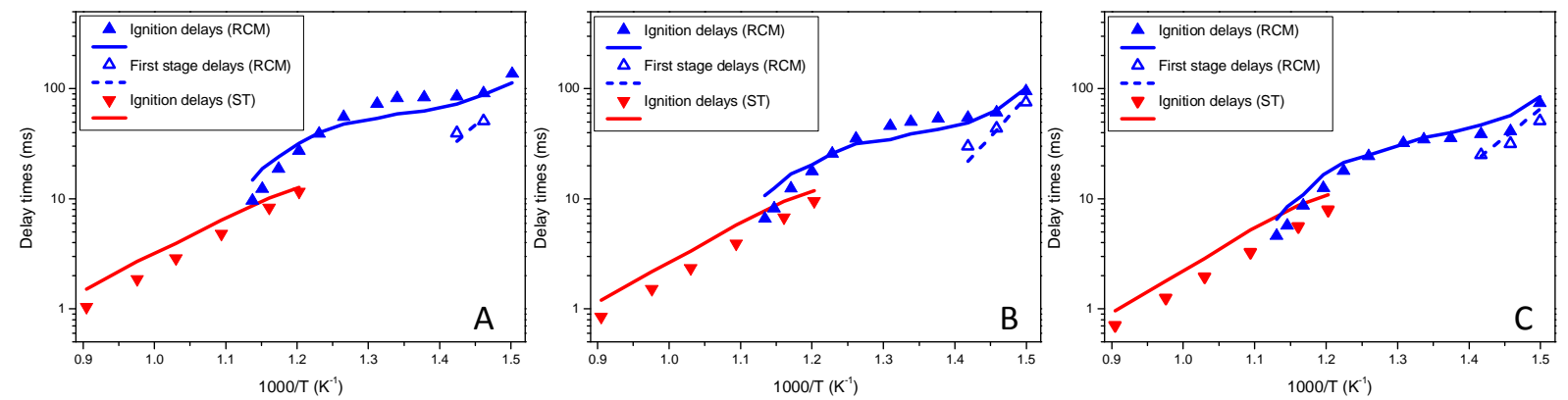

Figure 8 : Comparison between simulated (lines) and experimental (symbols) delay times of stoichiometric THF/02/inert mixture: red is for ST [7] ( $\boldsymbol{\nabla}$, full lines) and blue for RCM [8] (first stage: $\Delta$, short dashed lines; ignition: $\boldsymbol{\Lambda}$, full lines). (A) $\mathrm{p}_{\mathrm{TDC}}$ in the $\mathrm{RCM}=0.53-0.64 \mathrm{MPa}$; $\mathrm{p}$ in the $\mathrm{ST}=0.64 \mathrm{MPa}$. (B) $\mathrm{p}_{\mathrm{TDC}}$ in the $\mathrm{RCM}=0.63-0.77 \mathrm{MPa}$; $\mathrm{p}$ in the $\mathrm{ST}=0.77 \mathrm{MPa}$. (C) $\mathrm{p}_{\mathrm{TDC}}$ in the $\mathrm{RCM}=0.74-0.91 \mathrm{MPa}$; $\mathrm{p}$ in the $\mathrm{ST}=0.91 \mathrm{MPa}$. (For interpretation of the references to color in this figure legend, the reader is referred to the web version of this article.)

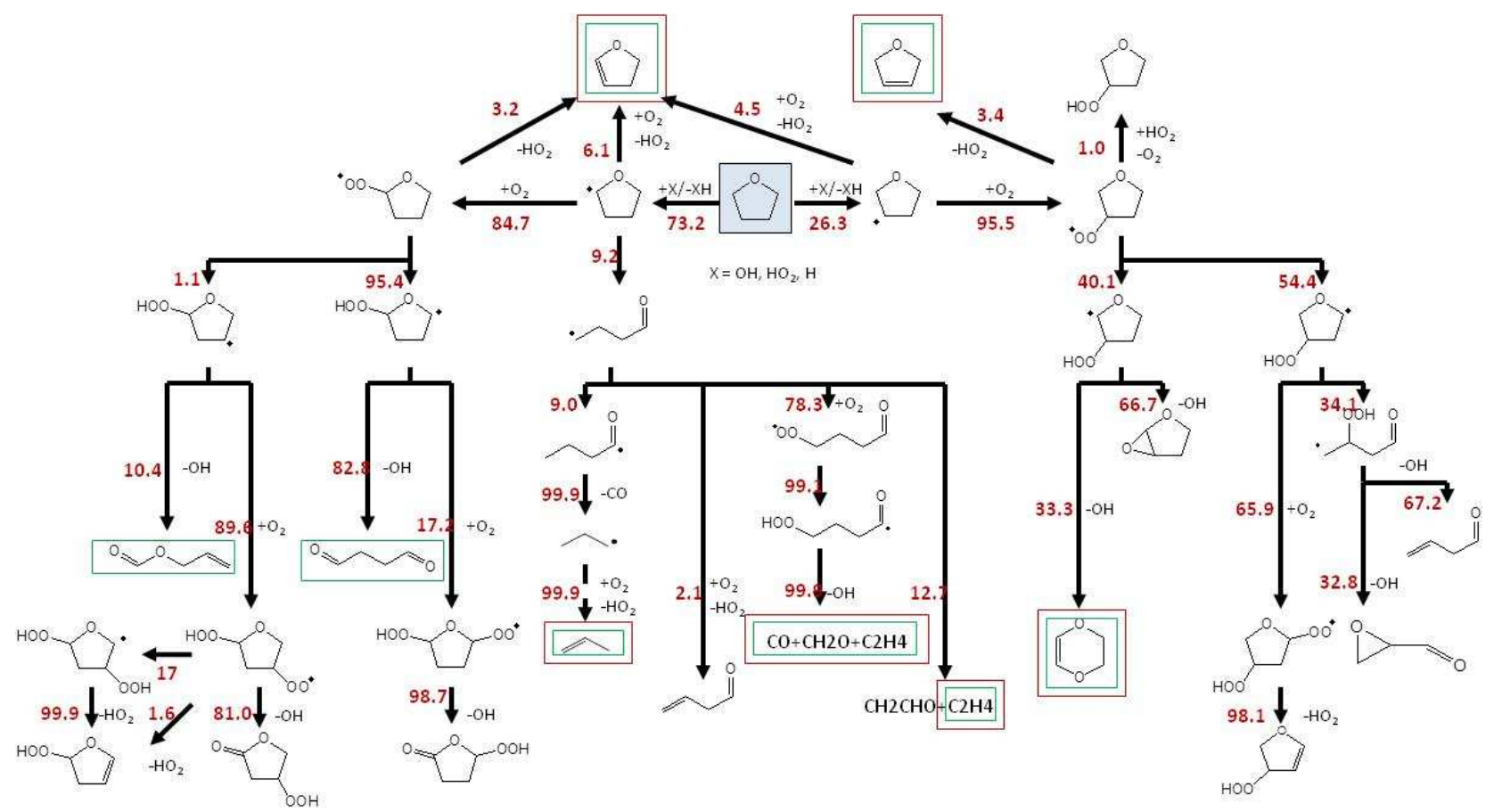

Figure 7 : Reaction-rate flux analysis of the primary pathways involved during THF oxidation in a JSR at $\phi=1, \mathrm{p}=0.106 \mathrm{MPa}, \tau=2 \mathrm{~s}$, and $\mathrm{T}=600 \mathrm{~K}$. Red numbers by the arrows depict the normalized rate of decomposition (in \%) of the species. Broken-line squares indicate species that were experimentally identified in a JSR, and full-line squares indicate species that were identified in a RCM [8]. Only rates above $1 \%$ are shown. 
Sensitivity analysis of the RCM ignition delay time at $680 \mathrm{~K}$ (Figure 9b) shows that sensitive reactions are generally the same as from the sensitivity analysis of the first-stage ignition delay time. The main difference is in the presence of the termination reaction $\mathrm{HO}_{2}+\mathrm{HO}_{2}=\mathrm{H}_{2} \mathrm{O}_{2}+\mathrm{O}_{2}$, consuming two $\mathrm{HO}_{2}$ radicals. This radical is key for converting THF into 2-tetrahydrofuranyl radical, the first step in the sequence responsible for increase of the reactivity at low temperature. When temperature is increased to $890 \mathrm{~K}$ (Figure 9c), the sensitivity coefficient for reaction $\mathrm{HO}_{2}+\mathrm{HO}_{2}=\mathrm{H}_{2} \mathrm{O}_{2}+\mathrm{O}_{2}$ is the highest, and this reaction therefore largely inhibits reactivity in the intermediate temperature range. The sensitivity analysis confirms that reactions forming 2-tetrahydrofuranyl radical contribute to promote reactivity. Examples include H-abstraction from THF by $\mathrm{HO} 2$ radical, showing a high negative sensitivity coefficient, as well as $\mathrm{H}$-abstraction from THF by $\mathrm{OH}$ radical. The reaction between THF and $\mathrm{HO}_{2}$ radical is an important source of $\mathrm{H}_{2} \mathrm{O}_{2}$, which, when the temperature and pressure increase, releases two $\mathrm{OH}$ radicals through $\mathrm{H}_{2} \mathrm{O}_{2}(+\mathrm{M})=\mathrm{OH}+\mathrm{OH}(+\mathrm{M})$ and promotes reactivity. On the other hand, the $\mathrm{H}$ abstraction reaction from $\mathrm{THF}$ by $\mathrm{OH}$ radical yielding 3-tetrahydrofuranyl radical inhibits reactivity even at intermediate temperatures.

At elevated temperatures like $1105 \mathrm{~K}$ (Figure $9 \mathrm{~d}$ ), the most sensitive reactions are from the $\mathrm{C}_{0}-\mathrm{C}_{4}$ base set: thermal decomposition of $\mathrm{H}_{2} \mathrm{O}_{2}(+\mathrm{M})=\mathrm{OH}+\mathrm{OH}(+\mathrm{M})$, whose effect was described previously, and the chainbranching reaction $\mathrm{H}+\mathrm{O}_{2}=\mathrm{O}+\mathrm{OH}$. This last reaction is characteristic of the high-temperature kinetics and relies on $\mathrm{H}$ atom presence. As a consequence, reactions that release an $\mathrm{H}$ atom promote reactivity, such as the $\mathrm{C}$ - $\mathrm{H}$ bond-breaking reaction of the 3-tetrahydrofuranyl radical forming 2,3-dihydrofuran and an $\mathrm{H}$ atom. By comparison, $\mathrm{H}$-abstraction by $\mathrm{H}$ atom from $\mathrm{THF}$, giving tetrahydrofuran-2-yl radical and $\mathrm{H}_{2}$, inhibits reactivity.
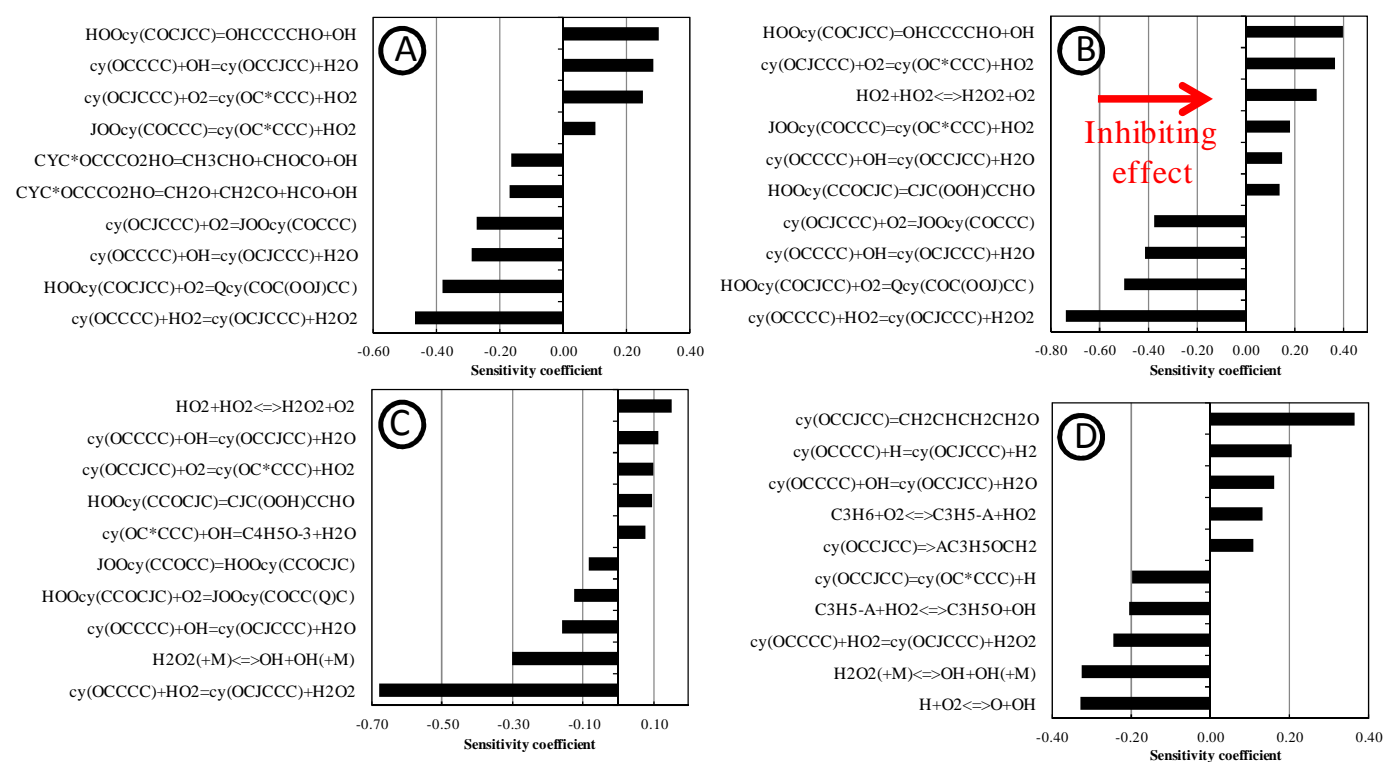

Figure 9 : Brute-force sensitivity analysis on the ignition delay times of THF/O2/inert mixtures: (a) firststage RCM ignition delay time at $680 \mathrm{~K}$ and $0.91 \mathrm{MPa}$; (b) total ignition RCM delay time at $680 \mathrm{~K}$ and $0.91 \mathrm{MPa}$; (c) total RCM ignition delay time at $890 \mathrm{~K}$ and $0.91 \mathrm{MPa}$; (d) shock-tube delay time at $1105 \mathrm{~K}$ and $0.91 \mathrm{MPa}$. 
Also, ring-opening reactions of 3-tetrahydrofuranyl radical (Figure 12) yield two radicals that further decompose into the allyl radical and formaldehyde. As the allyl radical is stabilized by resonance, these opening reactions inhibit reactivity. However, the reaction $\mathrm{C}_{3} \mathrm{H}_{5}-\mathrm{A}+\mathrm{HO}_{2}=\mathrm{C}_{3} \mathrm{H}_{5} \mathrm{O}+\mathrm{OH}$ converts a resonancestabilized allyl radical into an $\mathrm{OH}$ radical, and therefore has a negative sensitivity on the ignition delay at $1105 \mathrm{~K}$.

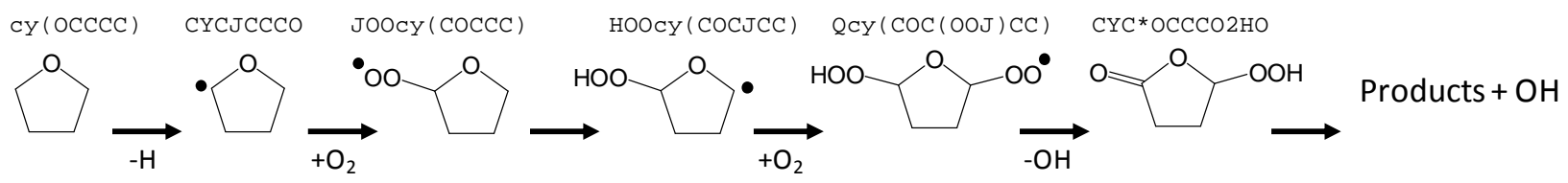

Figure 10 : Major sequence of reactions to explain promoting the reactivity during the first-stage ignition, based on flux analysis.

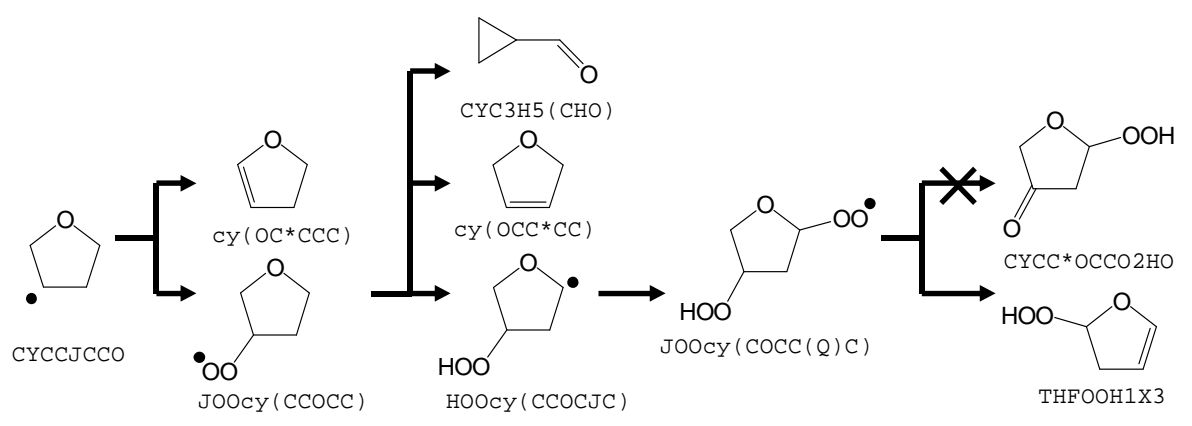

Figure 11 : Formation and fate of J00cy(COCC(Q)C) radical.

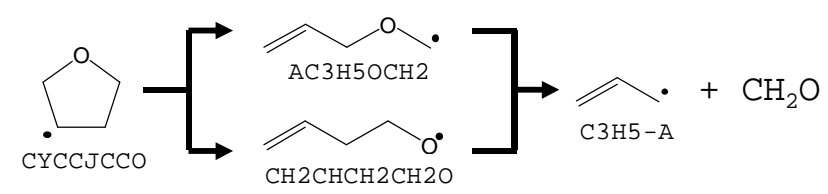

Figure 12 : Proposed formation route of allyl radical via ring opening reactions of 3-tetrahydrofuranyl radical.

\section{Conclusion}

The present paper proposes the first model for low-temperature THF oxidation based mainly on high-level theoretical calculations. In the case of tetrahydrofuranylperoxy isomerization and subsequent cyclic ether formation, significant different reaction rate coefficients are encountered when values would be estimated from alkane rate rules. Predictions from this model are overall in good agreement with a broad range of literature experimental measurements performed in JSRs, RCM, ST and flames. The current model explains the formation of most experimentally observed stable intermediates observed in JSR or RCM below $800 \mathrm{~K}$. For the JSR data $\mathrm{CO}$ and $\mathrm{CO}_{2}$ mole fraction predictions in the low-temperature reactivity region could be improved if secondary pathways leading to the formation of small oxygenated compounds such as oxirane or propanal, would be included. The new calculated kinetic values will be of help to develop models for substituted tetrahydrofurans, which will be proposed as new biofuels in the future. 


\section{Acknowledgments}

YF and GV thank the Région "Hauts de France", the Ministère de l'Enseignement Supérieur et de la Recherche (CPER Climibio), and the European Fund for Regional Economic Development. AG thanks the COST Action CM1404 "Chemistry of smart energy carriers and technologies", and the Fundação para a Ciência e a Tecnologia (FCT) for the SFRH/BPD/89722/2012 grant and the UID/MULTI/00612/2015 grant. The quantum chemical calculations were carried out using the STEVIN Supercomputer Infrastructure at Ghent University, funded by Ghent University, the Flemish Supercomputer Center (VSC), the Hercules Foundation and the Flemish Government - department EWI. HHC and KVG would like to acknowledge the financial support from the SBO proposal "Arboref" supported by the Institute for promotion of Innovation through Science and Technology in Flanders (IWT). PRW thanks the Université de Lorraine for support as "Professeur invité" during this work.

\section{Supplemental data}

- Supplementary description

- Kinetic model in CHEMKIN format, with thermochemical and transport data files

\section{References}

[1]L.D. Schmidt, P.J. Dauenhauer, Hybrid routes to biofuels. Nature 447 (2007) 914-915.

[2]J.S. Luterbacher, D.M. Alonso, J.A. Dumesic, Targeted chemical upgrading of lignocellulosic biomass to platform molecules, Green Chem. 16 (2014) 4816-4838.

[3]L.-S. Tran, M. Verdicchio, F. Monge, R.C. Martin, R. Bounaceeur, B. Sirjean, P.-A. Glaude, M.U. Alzueta, F. Battin-Leclerc, An experimental and modeling study of the combustion of tetrahydrofuran, Combust. Flame 162 (2015) 1899-1918.

[4]T.W. Rudolph, J.J. Thomas, NOx, NMHC and CO emissions from biomass derived gasoline extenders, Biomass 16, (1988) 33-49.

[5]O. Herbinet, B. Husson, Z. Serinyel, M. Cord, V. Warth, R. Fournet, P.-A. Glaude, B. Sirjean, F. Battin-Leclerc, Z. Wang, M. Xie, Z. Cheng, F. Qi, Experimental and modeling investigation of the low-temperature oxidation of n-heptane, Combust. Flame 159 (2012) 3455-3471.

[6]P. Dagaut, M. McGuinness, J.M. Simmie, M. Cathonnet, The ignition and oxidation of tetrahydrofuran: Experiments and kinetic modeling, Combust. Sci. Technol. 135 (1998) 3-29.

[7]Y.Y. Uygun, S. Ishihara, H. Olivier, A high pressure ignition delay time study of 2-methylfuran and tetrahydrofuran in shock tubes, Combust. Flame 161 (2014) 2519-2530.

[8]G. Vanhove, Y. Yu, M.A. Boumehdi, O. Frottier, O. Herbinet, P.-A. Glaude, F. Battin-Leclerc, Experimental study of tetrahydrofuran oxidation and ignition in low-temperature conditions, Energy Fuels 29 (2015) 6118-6125.

[9]I.O. Antonov, J. Zádor, B. Rotavera, E. Papajak, D.L. Osborn, C.A. Taatjes, L. Sheps, Pressure-dependent competition among reaction pathways from first- and second-02 additions in the low-temperature oxidation of tetrahydrofuran, J. Phys. Chem. A 120 (2016) 6582-6595.

[10] Y. Fenard, M.A. Boumehdi, G. Vanhove, Experimental and kinetic modeling study of 2methyltetrahydrofuran oxidation under engine-relevant conditions, Combust. Flame 178 (2017) 168181. 
[11] R. Tripathi, C. Lee, R.X. Fernandes, H. Olivier, H.J. Curran, S. Mani Sarathy, H. Pitsch, Ignition characteristics of 2-methyltetrahydrofuran: An experimental and kinetic study, Proc. Combust. Inst. 36 (2017) 587-595.

[12] L. Cai, H. Minwegen, J. Beeckmann, U. Burke, R. Tripathi, A. Ramalingam, L.C. Kröger, A. Sudholt, K. Leonhard, J. Klankermayer, K.A. Heufer, H. Pitsch, Experimental and numerical study of a novel biofuel: 2Butyltetrahydrofuran, Combust. Flame 178 (2017) 257-267.

[13] J. A. Montgomery, M. J. Frisch, J. W. Ochterski, G. A. Petersson, A complete basis set model chemistry. VI. Use of density functional geometries and frequencies, J. Chem. Phys. 110 (1999) 2822-2827.

[14] M.J. Frisch, G.W. Trucks, H.B. Schlegel, G.E. Scuseria, M.A. Robb, J.R. Cheeseman, G. Scalmani, V. Barone, B. Mennucci, G. A. Petersson, H. Nakatsuji, M. Caricato, X. Li, H.P. Hratchian, A. F. Izmaylov, J. Bloino, G. Zheng, J.L. Sonnenberg, M. Hada, M. Ehara, K. Toyota, R. Fukuda, J. Hasegawa, M. Ishida, T. Nakajima, Y. Honda, O. Kitao, H. Nakai, T. Vreven, J. A. Montgomery, J.E. Peralta, F. Ogliaro, M. Bearpark, J.J. Heyd, E. Brothers, K.N. Kudin, V. N. Staroverov, R. Kobayashi, J. Normand, K. Raghavachari, A. Rendell, J.C. Burant, S.S. Iyengar, J. Tomasi, M. Cossi, N. Rega, J.M. Millam, M. Klene, J.E. Knox, J.B. Cross, V. Bakken, C. Adamo, J. Jaramillo, R. Gomperts, R E. Stratmann, O. Yazyev, A.J. Austin, R. Cammi, C. Pomelli, J.W. Ochterski, R.L. Martin, K. Morokuma, V.G. Zakrzewski, G.A. Voth, P. Salvador, J.J. Dannenberg, S. Dapprich, A. D. Daniels, Farkas, J.B. Foresman, J.V. Ortiz, J. Cioslowski, D.J. Fox, in: Wallingford CT, 2009.

[15] A. D. Becke, Density-functional thermochemistry. III. The role of exact exchange. J. Chem. Phys., 98 (1993) 5648-5662.

[16] E. Martínez-Nuñez, An automated transition state search using classical trajectories initialized at multiple minima. Phys. Chem. Chem. Phys. 17 (2015) 14912-14921.

[17] E. Martínez-Nuñez, J. Comput. Chem. 2015, 36, 222-234.

[18] L.A. Curtiss, K. Raghavachari, P.C. Redfern, J.A. Pople, Assessment of Gaussian-2 and density functional theories for the computation of enthalpies of formation, J. Chem. Phys. 106 (1997) 1063-1079.

[19] Reaction Design. CHEMKIN-PRO 15151. San Diego: 2016.

[20] L. Cai, H. Pitsch, S.Y. Mohamed, V. Raman, J. Bugler, H. Curran, S.M. Sarathy, Optimized reaction mechanism rate rules for ignition of normal alkanes. Combust. Flame 173 (2016) 468-482.

[21] S. Tanaka, F. Ayala, J.C. Keck, A reduced chemical kinetic model for HCCI combustion of primary reference fuels in a rapid compression machine, Combust. Flame 133 (2003) 467-481.

[22] W.K. Metcalfe, S.M. Burke, S.S. Ahmed, H.J. Curran, A Hierarchical and Comparative Kinetic Modeling Study of C1-C2 Hydrocarbon and Oxygenated Fuels, Int. J. Chem. Kinet. 45 (2013) 638-675.

[23] Y. Li, C.-W. Zhou, H.J. Curran, An extensive experimental and modeling study of 1-butene oxidation, Combust. Flame. 181 (2017) 198-213.

[24] M.J. Al Rashidi, J.C. Mármol, C. Banyon, M.B. Sajid, M. Mehl, W.J. Pitz, S. Mohamed, A. Alfazazi, T. Lu, H.J. Curran, A. Farooq, S.M. Sarathy, Cyclopentane combustion. Part II. Ignition delay measurements and mechanism validation, Combust. Flame 183 (2017) 372-385.

[25] A. Ramalingam, K. Zhang, A. Dhongde, L. Virnich, H. Sankhla, H. Curran, A. Heufer, An RCM experimental and modeling study on $\mathrm{CH} 4$ and $\mathrm{CH} 4$ /C2H6 oxidation at pressures up to 160 bar, Fuel. 206 (2017) 325-333.

[26] H. Minwegen, U. Burke, K.A. Heufer, An experimental and theoretical comparison of C3 -C5 linear ketones, Proc. Combust. Inst. 36 (2017).

[27] M. Verdicchio, B. Sirjean, L.S. Tran, P.A. Glaude, F. Battin-Leclerc, Unimolecular decomposition of tetrahydrofuran: Carbene vs. diradical pathways, Proc. Combust. Inst. 35 (2015) 533-541. 
[28] B.R. Giri, F. Khaled, M. Szőri, B. Viskolcz, A. Farooq, An experimental and theoretical kinetic study of the reaction of $\mathrm{OH}$ radicals with tetrahydrofuran, Proc. Combust. Inst. 36 (2017) 143-150.

[29] H.K. Chakravarty, R.X. Fernandes, Reaction Kinetics of Hydrogen Abstraction Reactions by Hydroperoxyl Radical from 2-Methyltetrahydrofuran and 2,5-Dimethyltetrahydrofuran, J. Phys. Chem. A 117 (2013) 5028-5041.

[30] W.J. Pitz, C.V. Naik, T.N. Mhaoldúin, C.K. Westbrook, H.J. Curran, J.P. Orme, J.M. Simmie, Modeling and experimental investigation of methylcyclohexane ignition in a rapid compression machine, Proc. Combust. Inst. 31 (2007) 267-275.

[31] F. Battin-Leclerc, Detailed chemical kinetic models for the low-temperature combustion of hydrocarbons with application to gasoline and diesel fuel surrogates, Prog. Energy Combust. Sci. 34 (2008) 440-498.

[32] C.F. Goldsmith, W.H. Green, S.J. Klippenstein, Role of $02+$ QOOH in Low-Temperature Ignition of Propane. 1. Temperature and Pressure Dependent Rate Coefficients, J. Phys. Chem. A 116 (2012) 33253346.

[33] S.M. Sarathy, S. Vranckx, K. Yasunaga, M. Mehl, P. O?wald, W.K. Metcalfe, C.K. Westbrook, W.J. Pitz, K. Kohse-H?inghaus, R.X. Fernandes, H.J. Curran, A comprehensive chemical kinetic combustion model for the four butanol isomers, Combust. Flame 159 (2012) 2028-2055.

[34] H.J. Curran, P. Gaffuri, W.J. Pitz, C.K. Westbrook, A comprehensive modeling study of n-heptane oxidation, Combust. Flame 114 (1998) 149-177.

[35] P.S. Veloo, P. Dagaut, C. Togbé, G. Dayma, S.M. Sarathy, C.K. Westbrook, F.N. Egolfopoulos, Experimental and modeling study of the oxidation of n- and iso-butanal, Combust. Flame 160 (2013) 1609-1626.

[36] F. Dubnikova, A. Lifshitz, Isomerization of 2,3-Dihydrofuran and 5-Methyl-2,3-dihydrofuran: Quantum Chemical and Kinetics Calculations, J. Phys. Chem. A 106 (2002) 1026-1034. 